\title{
Comparative analysis of hapalindole, ambiguine and welwitindolinone gene clusters and reconstitution of indole-isonitrile biosynthesis from cyanobacteria
}

Melinda L Micallef ${ }^{1 \dagger}$, Deepti Sharma ${ }^{2 \dagger}$, Brittney M Bunn², Lena Gerwick ${ }^{3}$, Rajesh Viswanathan ${ }^{2 *}$ and Michelle C Moffitt ${ }^{{ }^{*}}$

\begin{abstract}
Background: The hapalindole-type family of natural products is a group of hybrid isoprenoid-indole alkaloids, produced solely by members of the Subsection $V$ cyanobacterial strains. This family broadly includes the hapalindoles, welwitindolinones, fisherindoles and ambiguines amongst others, all of which have an isonitrile- or isothiocyanate-containing indole alkaloid skeleton, with a cyclized isoprene unit. The hapalindoles are diversified into the welwitindolinones, fischerindoles and ambiguines through the employment of tailoring oxygenase, methyltransferase and prenyltransferase enzymes. We compare the genetic basis for the biosynthesis of this diverse group of natural products and identify key early biosynthetic intermediates.

Results: Whole genome sequencing of freshwater and terrestrial cyanobacteria Westiella intricata UH strain HT-29-1, Hapalosiphon welwitschii UH strain IC-52-3, Fischerella ambigua UTEX 1903 and Fischerella sp. ATCC 43239 led to the identification of a candidate hapalindole-type gene cluster in each strain. These were compared with the recently published ambiguine and welwitindolinone gene clusters and four unpublished clusters identified within publicly available genomes. We present detailed comparative bioinformatic analysis of the gene clusters and the biosynthesis of a pivotal indole-isonitrile intermediate resulting in both cis and trans geometrical isomers. Enzyme analyses and metabolite extractions from two hapalindole-producing Fischerella strains indicate the presence of cis and trans indole-isonitriles as biosynthetic intermediates in the early steps of the pathway.
\end{abstract}

Conclusions: Interestingly, the organization of the welwitindolinone gene cluster is conserved in all producing strains but distinct from the hapalindole and ambiguine clusters. Enzymatic assays using Well1 and Well3 from Westiella intricata UH strain HT-29-1 demonstrated the ability to catalyze the formation of both cis and trans geometrical isomers when using a cell lysate. The enzymatic and metabolic characterization of both cis and trans indole-isonitrile intermediates implies conservation of their stereochemical integrity towards members of the ambiguine and welwitindolinone products. In summary, we present data that supports a unified biosynthetic pathway towards hapalindoles in nine individual species of cyanobacteria. Diversification of the pathway occurs later through the employment of specialized enzymatic steps towards fischerindoles, ambiguines and welwitindolinones.

\footnotetext{
* Correspondence: rajesh.viswanathan@case.edu; m.moffitt@uws.edu.au

${ }^{\dagger}$ Equal contributors

${ }^{2}$ Department of Chemistry, Case Western Reserve University, 2740 Millis

Science Center, Adelbert Road, 44106 Cleveland, OH, USA

${ }^{1}$ School of Science and Health, University of Western Sydney, School of

Science and Health, Locked Bag 1797, 2751 Penrith, NSW, Australia

Full list of author information is available at the end of the article
} 


\section{Background}

The hapalindole family of natural products is a group of hybrid isoprenoid-indole alkaloids. Specifically, the hapalindole family has been identified solely within the genera Hapalosiphon, Fischerella, Westiella and Westiellopsis [1], which belong to the Subsection V (also known as Stigonematales) order of cyanobacteria. The hapalindoletype natural products are a structurally fascinating group of compounds, with over 80 variations identified to date, and is defined by the presence of an isonitrile- or isothiocyanate-containing indole alkaloid skeleton, with a cyclized isoprene unit. Members of the hapaldinole family are then divided into several sub-families, which include the hapalindoles, welwitindolinones, fisherindoles, ambiguines, fischambiguines, hapalindolinones, hapaloxindoles and fontonamides [1].

Structural diversity within the hapalindole family is generated through variation in the pattern of terpene cyclization, chlorination, methylation, oxidation/reduction and additional prenylation. Remarkably, despite their structural similarities, each analogue displays unique bioactivities, ranging from anticancer bioactivity by $N$-methyl welwitindolinone $C$ isothiocyanate (Figure 1, 8b/27b) $[2,3]$, to antituberculosis activity of ambiguines $\mathrm{K}$ and $\mathrm{M}$, fischambiguine B (Figure 1, 17a, 18a, 23) [4,5] and hapalindoles $\mathrm{X}$ and $\mathrm{A}[6]$.

Recently, gene clusters responsible for ambiguine $(a m b)$ and welwitindolinone (wel) biosynthesis were identified from Fischerella ambigua UTEX 1903 and Hapalosiphon welwitschii UTEX B1830, respectively $[7,8]$. Key biosynthetic steps towards the formation of hapalindoles were characterized. In vitro characterization of AmbP3 confirmed the $a m b$ gene cluster was responsible for the biosynthesis of the ambiguines from hapalindole $G$ [7]. Furthermore, in vitro characterization of a methyltransferase, WelM, encoded only within the wel gene cluster, confirmed its involvement in the methylation of welwitindolinone $\mathrm{C}$ isothiocyanate to form $\mathrm{N}$-methylwelwitindolinone $C$ isothiocyanate [8].

In order to further investigate the relatively complex network of biosynthetic pathways leading to the biosynthesis of the hapalindole-type natural products, we chose to analyze four Subsection V cyanobacterial strains known to produce a range of these compounds (Figure 1). Fischerella sp. ATCC 43239 has been reported to produce four hapalindoles [9], whereas Fischerella ambigua UTEX1903 produces a range of hapalindoles, ambiguines and fischambiguines [4,5]. Multiple hapalindoles, fischerindoles and welwitindolinones have been reported to be produced by Hapalosiphon welwitschii UH strain IC-52-3, whilst three welwitindolinones have been reported from Westiella intricata UH strain HT-29-1 [10] (Figure 1). We aimed to identify a gene cluster responsible for the biosynthesis of these compounds in each strain, while also screening publicly available cyanobacterial genomes for the presence of the hapalindole-type biosynthetic gene cluster. The genetic analyses were complemented by in vitro enzymatic assays for the isonitrile biosynthesis enzymes WelI1 and WelI3, resulting in the formation of both cis and trans isoforms of 3-(2-isocyanovinyl)indole (hereafter known as indole-isonitrile). Furthermore, the enzymology is supported through structural verification of both cis and trans isoforms of the indole-isonitrile extracted directly from Fischerella sp. and Fischerella ambigua cultures.

\section{Results and discussion}

Whole genome sequencing of Fischerella sp. ATCC 43239 (hereafter known as FS ATCC43239), Fischerella ambigua UTEX 1903 (hereafter known as FA UTEX1903), Hapalosiphon welwitschii UH strain IC-52-3 (hereafter known as HW IC-52-3) and Westiella intricata UH strain HT-29-1 (hereafter known as WI HT-29-1) was used to identify a gene cluster encoding the biosynthesis of the hapalindoles (precursor molecules for fischerindole, ambiguine and welwitindolinone biosynthesis) in each strain. Candidate gene clusters were identified in all four sequenced genomes, and PCR reactions were used to seal any gaps. The wel (welwitindolinone) gene cluster was identified in the genome of WI HT-29-1 (Additional file 1: Table S1), and in the genome of HW IC-52-3 (Additional file 1: Table S2). The hpi (hapalindole) gene cluster was identified in the FS ATCC43239 genome (Additional file 1: Table S3).

The ambiguine $(a m b)$ gene cluster was recently published by Hillwig et al. [7]. We independently sequenced and identified the $a m b$ gene cluster from the genome of FA UTEX1903 as part of this study. While the majority of the nucleotide sequence is $100 \%$ identical, some differences upstream of the 3' end of $a m b E 3$ were identified. The $a m b$ gene cluster from Hillwig et al. [7] encodes ParA and ParB family chromosome partitioning proteins and transposases, however, the $a m b$ gene cluster sequenced in this study does not contain these genes, instead, genes encoding monooxygenases and oxidoreductases were identified (Additional file 1: Table S4).

There are currently 11 Subsection V cyanobacteria draft genomes that are publicly available. We screened all Subsection V genomes in an attempt to identify any additional gene clusters encoding the biosynthesis of the hapalindole group of compounds. There has been no reported investigation of hapalindole-type natural products from these strains. We have identified a gene cluster from Fischerella sp. PCC 9339 (hereafter known as FS PCC9339) (Additional file 1: Table S5), Fischerella sp. PCC 9431 (hereafter known as FS PCC9431) (Additional file 1: Table S6) and Fischerella muscicola SAG 1427-1 (hereafter known as FM SAG1427-1) (Additional file 1: Table S7) (Table 1). 
A)

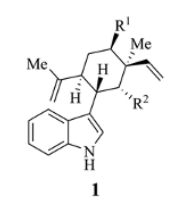

1a. $\mathrm{R}^{1}=\mathrm{H}, \mathrm{R}^{2}=\mathrm{NC} \quad 12$-epi-hapalindole $\mathrm{C}$ isonitrile 1b. $\mathrm{R}^{1}=\mathrm{H}, \mathrm{R}^{2}=\mathrm{NCS}$ 12-epi-hapalindole $\mathrm{D}$ isothiocyanate

1c. $\mathrm{R}^{1}=\mathrm{Cl}, \mathrm{R}^{2}=\mathrm{NC} \quad 12$-epi-hapalindole $\mathrm{E}$ isonitrile

1d. $\mathrm{R}^{1}=\mathrm{Cl}, \mathrm{R}^{2}=\mathrm{NCS}$ 12-epi-hapalindole $\mathrm{F}$ isothiocyanate

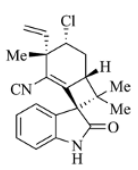

5

welwitindolinone $\mathrm{A}$ isonitrile 6a. $\mathrm{R}^{3}=\mathrm{H}$ welwitindolinone $\mathrm{B}$ isothiocyanate 6b. $\mathrm{R}^{3}=\mathrm{Me} N$-methyl-welwitindolinone B isothiocyanate

B)

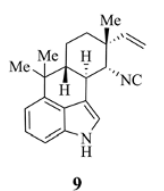

hapalindole $\mathrm{H}$ isonitrile

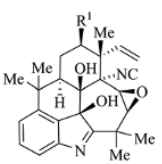

13a. $\mathrm{R}^{1}=\mathrm{Cl}$ ambiguine $\mathrm{D}$ isonitrile 13b. $\mathrm{R}^{\mathrm{l}}=\mathrm{H}$ ambiguine $\mathrm{J}$ isonitrile

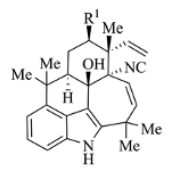

17

17a. $\mathrm{R}^{1}=\mathrm{Cl}$ ambiguine $\mathrm{K}$ isonitrile 17b. $\mathrm{R}^{1}=\mathrm{H}$ ambiguine $\mathrm{L}$ isonitrile

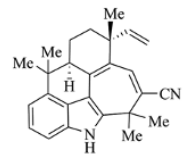

21

ambiguine $\mathrm{Q}$ nitrile

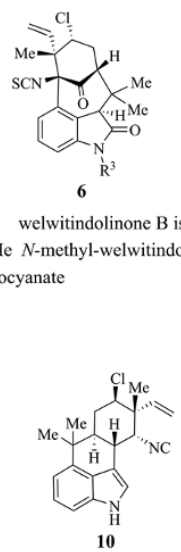

hapalindole $\mathrm{G}$ isonitrile

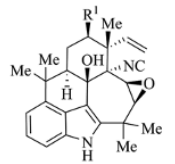

14

14a. $\mathrm{R}^{1}=\mathrm{Cl}$ ambiguine $\mathrm{E}$ isonitrile 14b. $\mathrm{R}^{1}=\mathrm{H}$ ambiguine $\mathrm{I}$ isonitrile

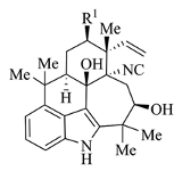

18

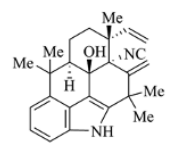

22

fischambiguine $\mathrm{A}$ 18a. $\mathrm{R}^{\mathrm{l}}=\mathrm{Cl}$ ambiguine $\mathrm{M}$ isonitrile 18b. $\mathrm{R}^{1}=\mathrm{H}$ ambiguine $\mathrm{N}$ isonitrile

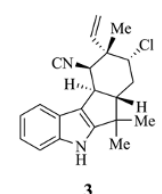

12-epi-fischerindole $\mathrm{G}$ isonitrile

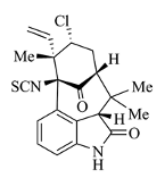

7

3-epi-welwitindolinone $\mathrm{B}$ isothiocyanate

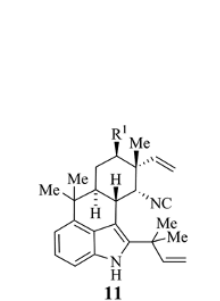

11a. $\mathrm{R}^{1}=\mathrm{Cl}$ ambiguine $\mathrm{A}$ isonitrile 11b. $\mathrm{R}^{1}=\mathrm{H}$ ambiguine $\mathrm{H}$ isonitrile

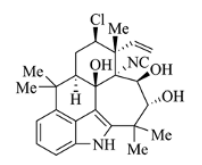

15

ambiguine $\mathrm{F}$ isonitrile

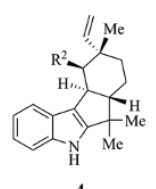

4a. $\mathrm{R}^{2}=\mathrm{NC}$ fischerindole $\mathrm{U}$ isonitrile

4b. $\mathrm{R}^{2}=\mathrm{NCS}$ fischerindole $\mathrm{U}$ isothiocyanate

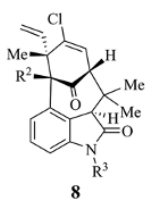

8a. $\mathrm{R}^{2}=\mathrm{NCS}, \mathrm{R}^{3}=\mathrm{H} \quad$ welwitindolinone $\mathrm{C}$

isothiocyanate

8b. $\mathrm{R}^{2}=\mathrm{NCS}, \mathrm{R}^{3}=$ Me $N$-methyl-welwitindolinone C isothiocyanate

8c. $\mathrm{R}^{2}=\mathrm{NC}, \mathrm{R}^{3}=\mathrm{Me} \quad N$-methyl-welwitindolinone $\mathrm{C}$ isonitrile

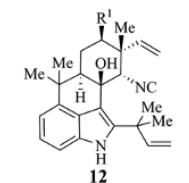

12a. $\mathrm{R}^{1}=\mathrm{Cl}$ ambiguine $\mathrm{B}$ isonitrile 12b. $R^{1}=H$ ambiguine $C$ isonitrile

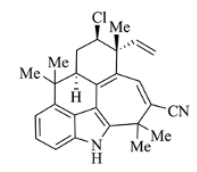

16

ambiguine $\mathrm{G}$ nitrile

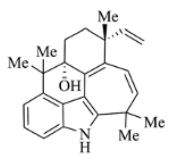

20

ambiguine $P$

C)

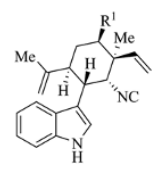

24

24a. $\mathrm{R}^{1}=\mathrm{H}$ 12-epi-hapalindole $\mathrm{C}$ isonitrile 24b. $\mathrm{R}^{1}=\mathrm{Cl} 1$ 12-epi-hapalindole $\mathrm{E}$ isonitrile

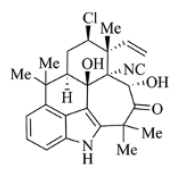

ambiguine $\mathrm{O}$ isonitrile

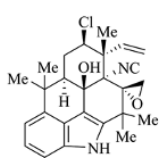

23

fischambiguine B

Figure 1 Structures of hapalindole family of natural products isolated from the strains sequenced in this study. A) Hapalindoles, fischerindoles and welwitindolinones isolated from Hapalosiphon welwitschii UH strain IC-52-3. B) Hapalindoles, ambiguines and fischambiguines isolated from Fischerella ambigua UTEX 1903. C) Hapalindoles isolated from Fischerella sp. ATCC 43239. D) Welwitindolinones isolated from Westiella intricata UH strain HT-29-1. 
Table 1 Comparison of the nine hpi, amb and wel biosynthetic gene clusters

\begin{tabular}{lllll}
\hline Name of organism & Length of gene cluster $(\mathbf{k b}):$ & Number of genes: & Name of gene cluster: & Reference: \\
\hline Fischerella sp. ATCC 43239 & 40.2 & 30 & hpi & This study \\
\hline Fischerella sp. PCC 9339 & 44.9 & 35 & hpi & This study \\
\hline Fischerella ambigua UTEX 1903 & 42 & 32 & amb & [7] \\
\hline Fischerella ambigua UTEX 1903 & 50.7 & 37 & amb & This study \\
\hline Hapalosiphon welwitschii UTEX B1830 & 36 & 30 & wel & This study \\
\hline Westiella intricata UH strain HT-29-1 & 59.3 & 47 & wel & This study \\
\hline Hapalosiphon welwitschii UH strain IC-52-3 & 55.8 & 45 & wel & This study \\
\hline Fischerella sp. PCC 9431 & 57.1 & 45 & wel & wel \\
\hline Fischerella muscicola SAG 1427-1 & 25.1 & 20 & This study \\
\hline
\end{tabular}

*The exact length of this gene cluster was unable to be determined due to sequencing gaps in two genes located at the $5^{\prime}$ end of the gene cluster.

Prior to submission of this manuscript, the identification and characterization of the wel gene cluster from $H$. welwitschii UTEX B1830 was published by Hillwig et al. [8] (hereafter known as HW UTEXB1830). As the nucleotide sequence was not available at the time of submission, we were unable to perform any analysis using this data. However, based on the image presented in the manuscript, this gene cluster demonstrates remarkable similarity to the wel gene clusters identified in this study (Figure 2).

\section{Comparisons of the hpi, amb and wel gene clusters}

The identification of these seven gene clusters, along with the recently published $a m b$ and wel gene clusters, allows genetic comparisons to be performed.
The nomenclature of genes used in this report follows those in the previously published $a m b$ and wel gene clusters $[7,8]$. For simplicity, a gene common to all gene clusters is referred to only by the corresponding letter and number. We have identified a core set of 19 genes common to the cyanobacterial strains analyzed in this study (Table 2). These common genes include the tryptophan biosynthesis genes T1-5 and C2, the isonitrile biosynthesis genes I1-3, the isoprenoid biosynthesis genes $D 1-4$, the geranyl pyrophosphate synthase gene $P 2$, the hapalindole-specific aromatic prenyltransferase gene $P 1$, the regulatory protein-encoding genes $R 1$ and $R 2$, as well as $C 1$ and $C 3$ (which encode other enzymes). These 19 genes share greater than $92 \%$ sequence identity at the protein level.

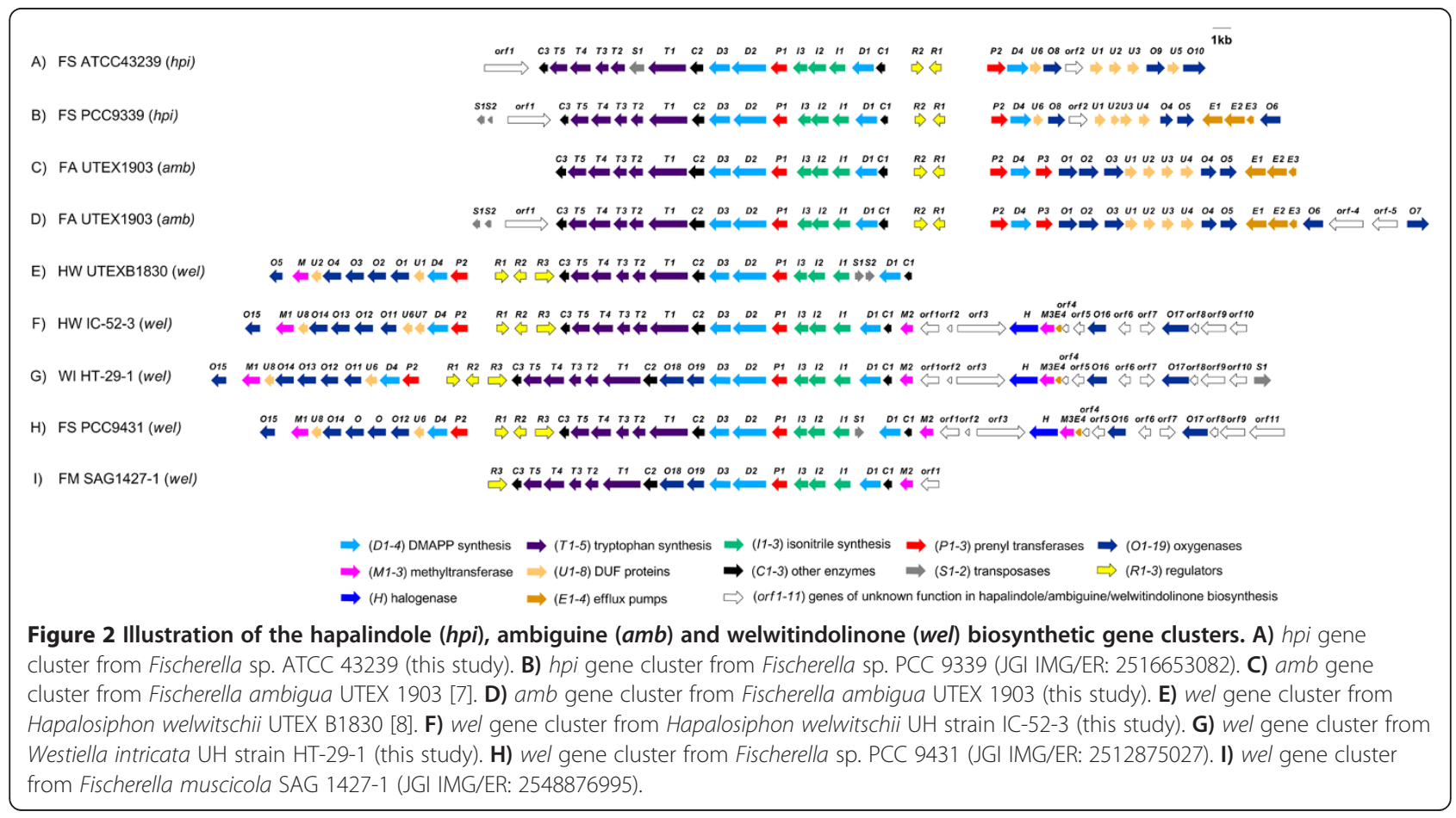


Table 2 Protein names, putative function, and \% identity of the encoded Hpi, Amb and Wel enzymes

\begin{tabular}{|c|c|c|c|c|c|c|c|c|}
\hline Enzyme & $\begin{array}{l}\text { FS ATCC } \\
43239\end{array}$ & $\begin{array}{l}\text { FS PCC } \\
9339\end{array}$ & $\begin{array}{l}\text { FA UTEX } \\
1903 \\
\end{array}$ & $\begin{array}{l}\text { HW } \\
\text { IC-52-3 }\end{array}$ & $\begin{array}{l}\text { WI } \\
\text { HT-29-1 }\end{array}$ & $\begin{array}{l}\text { FS PCC } \\
9431\end{array}$ & $\begin{array}{l}\text { FM SAG } \\
1427-1 \\
\end{array}$ & $\%$ identity* \\
\hline \multicolumn{9}{|l|}{ Tryptophan biosynthesis: } \\
\hline TrpE & HpiT1 & HpiT1 & AmbT1 & WelT1 & WelT1 & WelT1 & WelT1 & 93.3 \\
\hline TrpC & HpiT2 & HpiT2 & AmbT2 & WelT2 & WelT2 & WelT2 & WelT2 & 92 \\
\hline$\overline{T r p A}$ & HpiT3 & HpiT3 & AmbT3 & WelT3 & WelT3 & WelT3 & WelT3 & 92.7 \\
\hline TrpB & HpiT4 & HpiT4 & AmbT4 & WelT4 & WelT4 & WelT4 & WelT4 & 95.7 \\
\hline TrpD & HpiT5 & HpiT5 & AmbT5 & WelT5 & WelT5 & WelT5 & WelT5 & 94.8 \\
\hline DAHP synthase & HpiC2 & HpiC2 & AmbC2 & WelC2 & WelC2 & WelC2 & WelC2 & 95.3 \\
\hline \multicolumn{9}{|l|}{ IPP and DMAPP biosynthesis: } \\
\hline Dxr & HpiD1 & HpiD1 & AmbD1 & WelD1 & WelD1 & WelD1 & WelD1 & 96.4 \\
\hline Dxs & HpiD2 & HpiD2 & AmbD2 & WelD2 & WelD2 & WelD2 & WelD2 & 97.7 \\
\hline$\overline{I s p G}$ & HpiD3 & HpiD3 & AmbD3 & WelD3 & WelD3 & WelD3 & WelD3 & 98.7 \\
\hline $\mathrm{IspH}$ & HpiD4 & HpiD4 & AmbD4 & WelD4 & WelD4 & WelD4 & - & 95.3 \\
\hline \multicolumn{9}{|l|}{ Isonitrile biosynthesis: } \\
\hline $\sin A$ & Hpil1 & Hpil1 & Ambl1 & Well1 & Well1 & Well1 & Well1 & 94 \\
\hline $\sin A$ & Hpil2 & Hpil2 & Ambl2 & Well2 & Well2 & Well2 & Well2 & 96.2 \\
\hline $\operatorname{sn} B$ & Hpil3 & Hpil3 & Ambl3 & Well3 & Well3 & Well3 & Well3 & 95.6 \\
\hline \multicolumn{9}{|l|}{ Prenyltransferases: } \\
\hline Aromatic prenyltransferase & HpiP1 & HpiP1 & AmbP1 & WelP1 & WelP1 & WelP1 & WelP1 & 96.9 \\
\hline GPP & HpiP2 & HpiP2 & AmbP2 & WelP2 & WelP2 & WelP2 & - & 93 \\
\hline Aromatic prenyltransferase & - & - & AmbP3 & - & - & - & - & - \\
\hline \multicolumn{9}{|l|}{ Methyltransferases: } \\
\hline $\mathrm{N}$-methyltransferase & - & - & - & WelM1 & WelM1 & WelM1 & - & 98.8 \\
\hline SAM-dependent methyltransferase & - & - & - & WelM2 & WelM2 & WelM2 & WelM2 & 91.2 \\
\hline Histamine $\mathrm{N}$-methyltransferase & - & - & - & WelM3 & WelM3 & WelM3 & - & 99 \\
\hline \multicolumn{9}{|l|}{ Regulation proteins } \\
\hline $\begin{array}{l}\text { Response regulator containing a CheY-like } \\
\text { receiver domain and an HTH DNA-binding } \\
\text { domain }\end{array}$ & HpiR1 & HpiR1 & AmbR1 & WelR1 & WelR1 & WelR1 & - & 93.4 \\
\hline Transcriptional regulator, LuxR family & HpiR2 & HpiR2 & AmbR2 & WelR2 & WelR2 & WelR2 & - & 96.2 \\
\hline $\begin{array}{l}\text { Response regulator with CheY-like receiver } \\
\text { domain and winged-helix DNA-binding } \\
\text { domain }\end{array}$ & - & - & - & WelR3 & WelR3 & WelR3 & WelR3 & 93.3 \\
\hline \multicolumn{9}{|l|}{ Other: } \\
\hline Dephospho-CoA kinase-like protein & HpiC1 & HpiC1 & $\mathrm{AmbC1}$ & WelC1 & WelC1 & WelC1 & WelC1 & 93.2 \\
\hline Phosphoglycerate mutase family protein & HpiC3 & HpiC3 & AmbC3 & WelC3 & WelC3 & WelC3 & Welc3 & 96.4 \\
\hline \multicolumn{9}{|l|}{ Transporter genes: } \\
\hline DevC protein & - & HpiE1 & AmbE1 & - & - & - & - & 98.2 \\
\hline ABC exporter membrane fusion protein, DevB family & - & HpiE2 & AmbE2 & - & - & - & - & 99.7 \\
\hline Conserved membrane hypothetical protein & - & HpiE3 & AmbE3 & - & - & - & - & 100 \\
\hline Small multidrug resistance protein & - & - & - & WelE4 & WelE4 & WelE4 & - & 97.8 \\
\hline
\end{tabular}

*The \% identity is based on comparison of all enzymes sequenced.

\section{Organization of genes}

Comparison of the gene organization of the hpi/amb/wel gene clusters identified groups of genes whose order and orientation are conserved, however, the presence/absence of specific genes distinguish the $h p i$, $a m b$ and wel gene clusters from each other (Figure 2). These differences are probably essential in forming the given hapalindole-type natural products.

Within the hpi/amb/wel gene clusters analyzed, there appears to be two major transcripts, which were predicted based on the direction of the genes (Figure 2). The first predicted major transcript begins at C1. There are 15 
genes $(C 1, D 1, I 1, I 2, I 3, P 1, D 2, D 3, C 2, T 1, T 2, T 3, T 4, T 5$ and $C 3$ ) present on this predicted transcript in all nine gene clusters, in which the arrangement and orientation of the genes has been conserved. However, there are additional genes located within this predicted transcript in a few strains. In the $h p i$ gene cluster from FS ATCC43239, there is a single transposase located between $T 2$ and $T 1$. There are two transposases located between $I 1$ and $D 1$ in the wel gene cluster from HW UTEXB1830, and there is a single transposase located between $I 1$ and D1 in the gene cluster from FS PCC9431. There are also two oxygenase genes, $\mathrm{O} 18$ and O19, located between $C 2$ and $D 3$ in the gene clusters from WI HT-29-1 and FM SAG1427-1. The gene clusters from WI HT-29-1, HW IC-52-3, FS PCC9431 and FM SAG1427-1 also contain two additional conserved genes (orf 1 and M2), located at the beginning of this predicted transcript. In some gene clusters, orf2 is also located at the beginning of this predicted transcript. Given that the known welwitindolinone-producing strains contain these genes on the same predicted transcript with several other key genes in the biosynthetic pathway, these additional genes may be important in the biosynthesis of the welwitindolinones.

The second predicted major transcript in the hpi/amb/ wel gene clusters begins with the gene $P 2$ and is present in all the gene clusters identified in this study, except the gene cluster from FM SAG1427-1. In the hpi and $a m b$ gene clusters, this major predicted transcript is located upstream of the 5 ' end of $C 1$, however, in the wel gene clusters, the predicted transcript is located downstream of the 3' end of C3 (Figure 2). A number of oxygenase genes and sequence-redundant domain of unknown function (DUF) genes are found on these predicted transcripts, which vary between each gene cluster. The differences in these oxygenase and DUF genes are likely related to differences in the natural products produced.

There are additional predicted transcripts in the gene clusters from FS PCC9339 and the amb gene clusters. Downstream of the 3 ' end of $O 5$, the exporter genes $E 1$, $E 2$, and $E 3$ are all potentially transcribed on a single transcript. In the gene cluster from FS PCC9339 and the $a m b$ gene cluster sequenced in this study, the gene $O 6$ is also possibly located on this transcript. In the $a m b$ gene cluster sequenced in this study, $O 7$ is predicted to be located on a separate transcript.

The genes clusters from HW IC-52-3, WI HT-29-1 and FS PCC9431 contain five additional predicted transcripts upstream of the 5' end of orf2, which are highly conserved (greater than $98 \%$ identity at the nucleotide level). These genes are not located in any of the hpi or amb gene clusters, suggesting these genes may encode proteins responsible for welwitindolinone biosynthesis.
The regulatory genes $R 1, R 2$ and $R 3$ do not seem to form an operon, and the arrangement and orientation of these genes between each other are conserved in the gene clusters from HW UTEXB1830, HW IC-52-3, WI HT-29-1 and FS PCC9431.

By comparing the identified hapalindole-like natural products with their encoded gene clusters and proposed biosynthesis, the presence/absence of specific genes may be used to predict which class of hapalindole-type natural products (either hapalindole, ambiguines or welwitindolinones) may be produced from newly identified gene clusters. For example, the presence of AmbP3 suggests the ability to produce the ambiguines. This knowledge was used to infer the biosynthesis of the hapalindole-type natural products from FS PCC9339, FS PCC9431 and FM SAG1427-1, since the metabolite profile of these organisms has not been determined. It is likely that the gene cluster from FS PCC9339 encodes the biosynthesis of the hapalindoles, and the gene clusters from FS PCC9431 and FM SAG1427-1 encode the biosynthesis of the welwitindolinones. The gene cluster from FM SAG1427-1 was grouped with the wel gene clusters based on the presence and high similarity of the genes $018, O 19, R 3$ and $M 2$, all of which are specific to the wel gene clusters. However, the genes located on either side of the wel gene cluster from FM SAG1427-1 display no similarity to other genes in the wel gene clusters, and some highly conserved genes are missing. The absence of conserved core wel genes suggests the gene cluster may be non-functional in this strain.

In order to assess the mechanism of inheritance of hpi/amb/wel gene clusters within the Subsection V strains, we performed phylogenetic analysis of the $16 \mathrm{~S}$ rDNA (Figure 3). All of the strains that either contain the hpi/ $a m b / w e l$ gene cluster or are known producers of these molecules appear to be a monophyletic group, indicating that the gene cluster first appeared in a single ancestral strain. This is interesting, considering that some well-studied cyanobacterial natural products, such as microcystin and saxitoxin, exhibit a scattered distribution across several genera $[11,12]$. Studies suggest that the scattered distribution of these molecules occurs as a result of horizontal gene transfer [11-13]. The hapalindole family of molecules, however, appears to have been only inherited vertically to each of the descendant strains. This pattern of inheritance is also supported by a phylogenetic tree constructed using the prenyltransferase P1 protein sequence, which shows a similar clustering of sequences to the $16 \mathrm{~S}$ rDNA tree (Additional file 2). The conserved inheritance of these gene clusters implies that the hapalindole family of compounds plays an important role in the producing strains. 


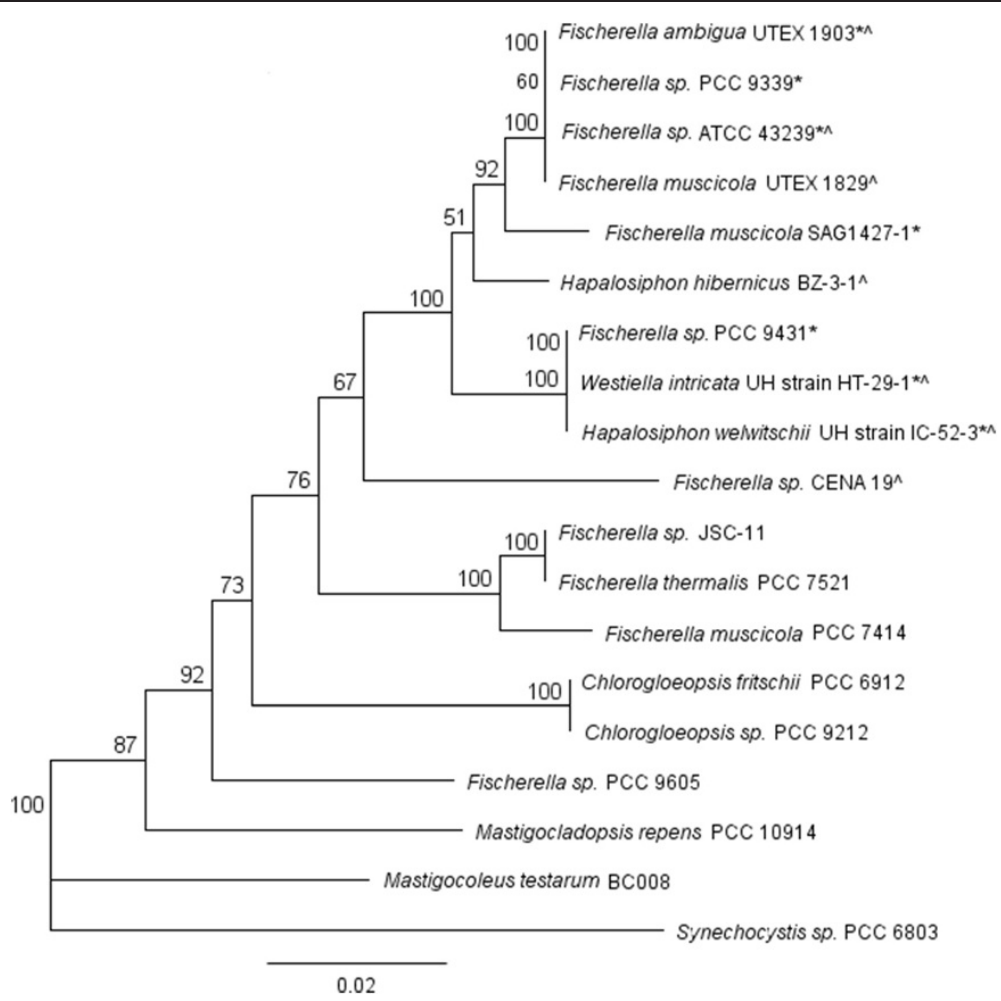

Figure 3 Phylogenetic analysis of Subsection V strains using 16S rDNA. Phylogenetic tree was constructed using a 929 bp fragment of the 165 rRNA gene from Subsection $V$ cyanobacterial strains analyzed in this study, Subsection $V$ cyanobacterial strains for which the genome has been sequenced, and cyanobacterial strains known to produce hapalindole-type natural products. Fischerella muscicola UTEX 1829 [GenBank: AB075984], Fischerella sp. PCC 9339 [IMG Gene ID: 2517062088], Fischerella sp. ATCC 43239 [GenBank: KJ768872], Fischerella ambigua UTEX 1930 [GenBank: KJ768871], Fischerella muscicola SAG 1427-1 [GenBank: AB075985], Fischerella sp. PCC 9431 [IMG Gene ID: 2512976007], Hapalosiphon welwitschii UH strain IC-52-3 [GenBank: KJ767019], Westiella intricata UH strain HT-29-1 [GenBank: KJ767016], Hapalosiphon hibernicus BZ-3-1 [GenBank: EU151900], Fischerella sp. CENA 19 [GenBank: AY039703], Fischerella sp. JSC-11 [GenBank: HM636645], Fischerella thermalis PCC 7521 [GenBank: AB075987], Fischerella muscicola PCC 7414 [GenBank: AB075986], Chlorogloeopsis fritschii PCC 6912 [GenBank: AB093489], Chlorogloeopsis fritschii PCC 9212 [GenBank: AB075982], Fischerella sp. PCC 9605 [IMG Gene ID: 2516144612], Mastigocladopsis repens PCC 10914 [GenBank: AJ544079], Mastigocoleus testarum BC 008 [IMG Gene ID: 2264826627] and Synechocystis sp. PCC 6803 [GenBank: NR_074311]. *indicates hpi/amb/wel gene cluster was identified in these strains. ^ indicates these strains are known producers of hapalindole-family of natural products. Synechocystis sp. PCC 6803 was used as the outgroup. Phylogenetic trees were constructed using the Geneious Tree Builder program, using the neighbour-joining method. Numbers at each branch point are the bootstrap values for percentages of 100 replicate trees.

\section{Tryptophan biosynthesis}

Five of the six essential genes required for the biosynthesis of L-tryptophan from chorismate, which are paralogues of $\operatorname{trp} A B C D E$ (T1-5), were identified in all nine biosynthetic gene clusters [14]. The sixth gene, $\operatorname{trp} F$, a phosphoribosylanthranilate isomerase gene, is located outside of the gene cluster consistently in all strains analyzed. Analysis of the genomes sequenced in this study revealed some cyanobacterial strains also contain a second set of genes which encode for tryptophan biosynthesis, however, other strains only contain the tryptophan genes within the gene cluster for tryptophan biosynthesis. Another gene common to all nine gene clusters is C2, a DAHP (3-deoxy-D-arabinoheptulosonate-7-phosphate) synthase gene, which encodes an enzyme regulating the biosynthesis of DAHP from the condensation of PEP (phosphoenolpyruvate) and erythrose-4-phosphate, the first enzymatic step of aromatic amino acid synthesis [15].

\section{Indole-isonitrile biosynthesis}

A signature chemical feature of the hapalindole family of alkaloids is the presence of an isonitrile functional group. The specific location of this functional group is conserved across all isonitrile-containing members and is at $\mathrm{C} 11$ of the hapalindole core (except for ambiguine $\mathrm{G}$ and $\mathrm{Q}$, where it has transposed into a nitrile functionality). The isonitrile biosynthesis genes I1-3 were identified and found to be tightly conserved in all clusters (greater than 94\% identity at the protein level across all gene clusters analyzed in this study). The gene products of $I 1$ and I2 demonstrate high sequence similarity to the previously characterized isonitrile synthases, IsnA (from an 
uncultured organism) [16] and PvcA (from Pseudomonas aeruginosa PA01) [17]. The six core motifs of IsnA and PvcA were identified in I1 and I2 (Additional file 3). The gene product of $I 3$ displayed high sequence similarity to the $\alpha$-ketoglutarate-dependent oxygenase, IsnB and PvcB $[16,17]$. We identified the amino acids of the metalbinding motif in all of the encoded protein sequences of I3 (Additional file 4).

Pathways encoded by Isn and Pvc require only one copy of each gene for the effective production of the isonitrile functional group from tryptophan [16,17]. However, all strains investigated in this study have a duplicated copy of $I 1$ (I2), with at least $78 \%$ identity between them at the protein level. Recent characterization of the set of isonitrile biosynthetic enzymes from the $a m b$ gene cluster identified that the enzymes AmbI1 and AmbI3 are responsible for the biosynthesis of the isonitrile functional group, however, the enzyme AmbI2 is functionallyredundant in isonitrile biosynthesis [7]. It is curious that this arrangement of three genes, containing the duplicated I1, has been maintained across all strains with very little evidence of mutation over time.

In order to establish the biosynthetic function of WelI1/I3 from the wel gene cluster of WI HT-29-1, these proteins were heterologously expressed and biosynthetic assays were performed using the Escherichia coli cell lysates (expressing WelI1/I3) with the proposed substrates L-tryptophan and ribose-5-phosphate, in the presence of ammonium iron sulfate and $\alpha$-ketoglutaric acid (Figure 4, A) [18]. An assay containing both enzymes was preferred to individual assays based on the instability of the first intermediate (L-Trp-isonitrile) during isolation (Figure 4, A) [18]. Prior to analyzing the enzymatic assay mixtures, chemically synthesized cis and trans isomers of indole-isonitrile (Additional file 5) were first identified as distinct traces with unique retention times (Figure 4, B1-3). HPLC analyses of enzymatic reaction mixtures after incubation for $16 \mathrm{~h}$ showed the presence of two major peaks, confirming the production of the cis and trans isomers of indole-isonitrile (Figure 4, B5). A nonenzymatic formation of the indole-isonitrile was ruled out based on a negative control (no WelI1/I3) (Figure 4, B4). Synthesized cis indole-isonitrile standard was incubated under the assay conditions as controls to test if isomerization was involved. Results indicate that the trans isomer is not formed through an E. coli-mediated isomerization (Figure 4, B6 and 7). However, there is a significant amount of degradation of the cis isomer observed after $16 \mathrm{~h}$ of incubation as compared to analysis after $3 \mathrm{~h}$ (Figure 4, B7 compared to 6). As a further measure of validation, we co-injected cis and trans indole-isonitriles to samples where enzymatic product formation was observed (Figure 4, B8) and only the two product peaks that correlated to the retention times of cis and trans indole-isonitriles were observed. Finally, additional confirmation for indole-isonitrile biosynthesis was obtained through LC-MS analyses under negative ion-mode (Additional file 6). Overall, the assay results validated the formation of cis and trans indole-isonitriles as the biosynthetic products of the pathway encoded by WelI1/I3. In contrast to AmbI1/3 and WelI1/3 from FA UTEX1903 and HW UTEXB1830 respectively, which only produce the cis isomer of the indole-isonitrile $[7,8]$, assay mixtures containing WelI1/I3 from WI HT-29-1 produced both the cis and trans isomers of the indole-isonitrile when the assay is carried out over a $16 \mathrm{~h}$ duration. Because a mixture of cis and trans products are observed for the first time, these are exciting observations from a natural product biosynthesis point of view, as they lead to interesting questions about the biochemical mechanism of WelI1/I3. It is probable that the enzymes are producing the trans isoform in concentrations below detection limit within the first $3 \mathrm{~h}$, which then accumulate over time and can be detected after $16 \mathrm{~h}$. However, it remains to be seen whether both of these isomers engage as substrates for downstream hapalindole-producing steps of the pathway.

Until now, direct evidence of the presence of indoleisonitriles from cyanobacterial cultures has remained elusive. Therefore, we set out to identify the presence of isonitrile intermediates through direct extraction from FS ATCC43239 and FA UTEX1903 cultures. Using synthetic standards, similar to the assay described above, a HPLC method was established in order to verify the presence of indole-isonitriles from cyanobacterial biomass. HPLC analyses identified both the cis and trans isomers of the indole-isonitrile in the extracts of FS ATCC43239 and FA UTEX1903 (Figure 5). To confirm the HPLC results, FS ATCC43239 and FA UTEX1903 cultures were extracted and analyzed by LC-MS under negative ion mode electrospray ionization, and the organic extract from both cultures displayed a $[\mathrm{M}-\mathrm{H}]^{+}$peak at $m / z 167$ consistent with that observed from the chemically synthesized standard. The HRESI-MS characterization for the synthesized indoleisonitrile displayed a parent $[\mathrm{M}]^{+}$peak at $\mathrm{m} / z 168.0689$ (expected $\mathrm{m} / z=168.0687$ ), while culture extracts from FS ATCC43239 and FA UTEX1903 displayed an indoleisonitrile $[\mathrm{M}]^{+}$peak at $\mathrm{m} / z 168.0685$ (within $5.95 \times 10^{-8}$ units from synthesized sample $=59 \mathrm{ppb}$ ) (Additional file 7). Thus, we report for the first time, the presence of both cis and trans isomers of indole-isonitrile in two Fischerella cultures as biosynthetic intermediates of the hapalindole pathway.

In concurrence with our enzymology observations, the detection of both cis and trans isomers from cyanobacterial extracts by HPLC analysis raised the possibility of inter-conversions and/or thermal isomerizations during the timescale of the analyses. Therefore, to rule out these possibilities, we subjected the cis isomer of the indole-isonitrile from synthesized standard to the identical extraction 


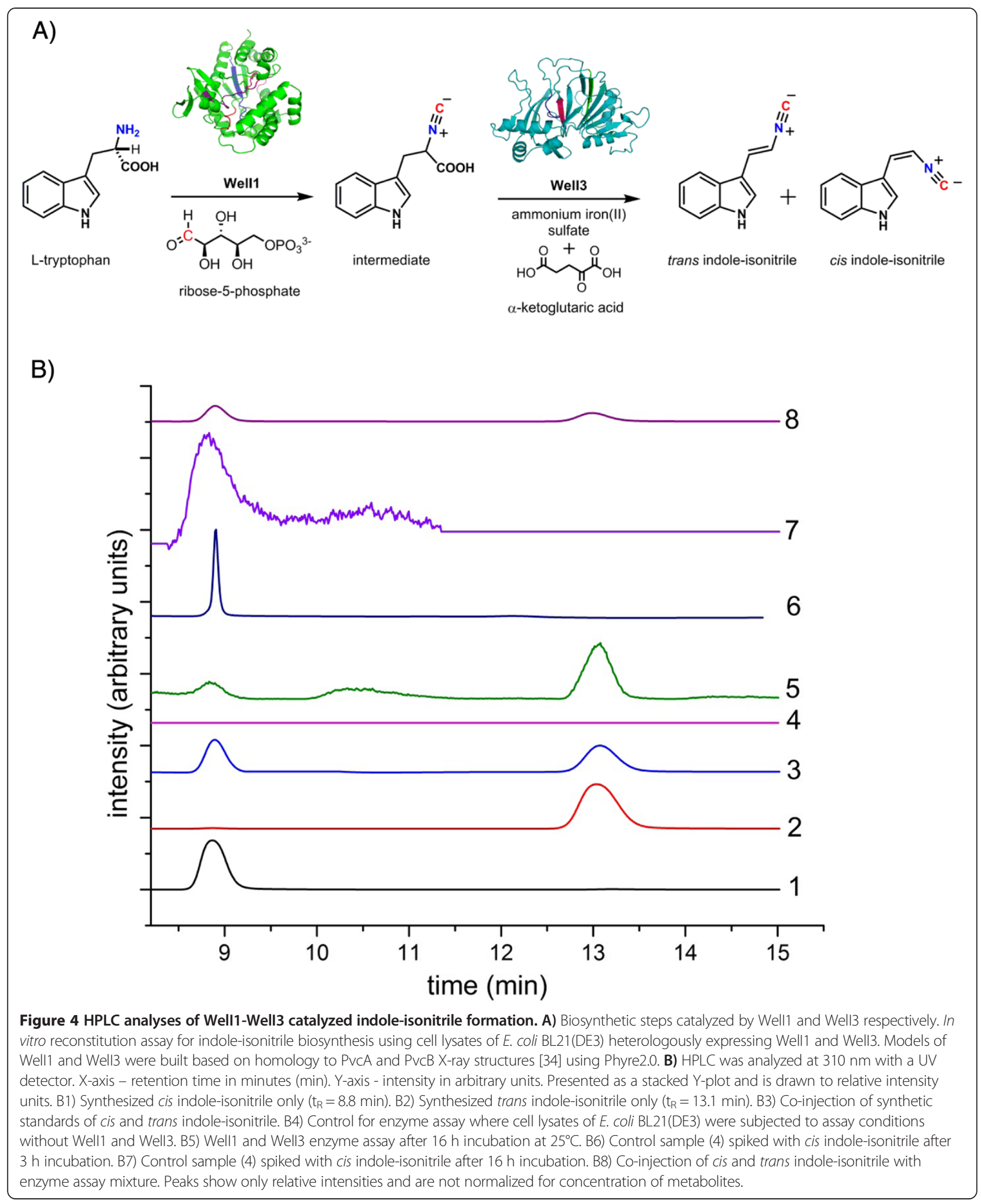

protocol performed on the native cyanobacterial cells. Only thermal degradation (no isomerization) was observed (similar to the enzymology observation over $16 \mathrm{~h}$ ). Overall, the stereochemical integrity of the individual cis and trans isomers was found to be maintained through the course of our isolation procedures. 


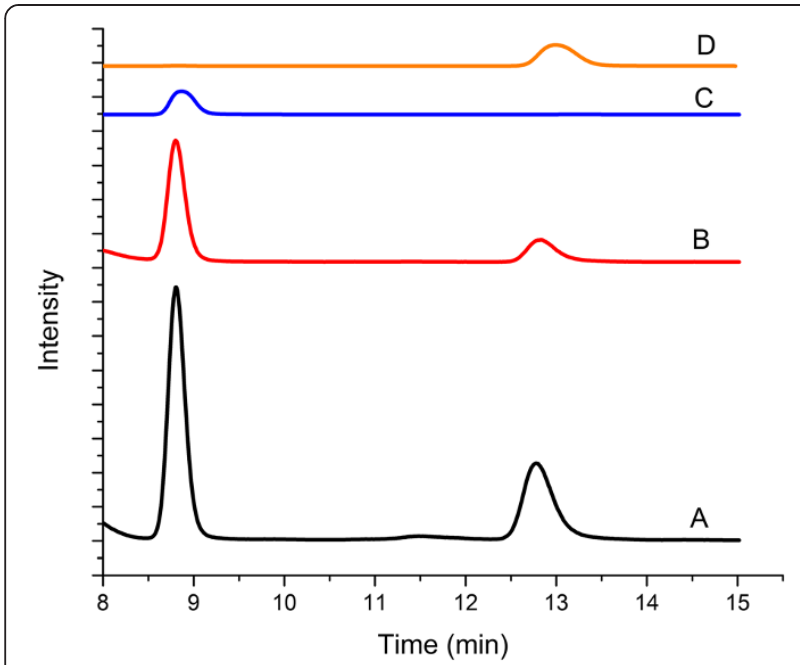

Figure 5 HPLC analyses of both cis and trans isomers of indole-isonitrile from culture extracts. HPLC was analyzed at $310 \mathrm{~nm}$ with a UV detector. X-axis - retention times in minutes (min). Y-axis refers to intensity in arbitrary units. Plot presented as a stacked $Y$-plot and is drawn to relative intensity units. A) FS ATCC43239 extracts. B) FA UTEX1903 extracts. C) Synthesized cis isomer ( $t_{R}=8.8 \mathrm{~min}$ ). D) Synthesized trans isomer ( $\left.t_{R}=13.1 \mathrm{~min}\right)$. Peaks show only relative intensities and are not normalized for concentration of metabolites.

Hapalindole products isolated from FS ATCC43239 strain display both cis and trans stereodisposition in their C10-C11 arrangement (Figure 1, 24a-b versus 25a-b), implying that both isomers are probable substrates in the subsequent step of the biosynthetic pathway. The presence of the trans isomer in extracts from FA UTEX1903 is intriguing considering ambiguines possess strictly a cis stereodisposition between C10-C11 stereocenters.

\section{Geranyl pyrophosphate biosynthesis}

The other proposed substrate for hapalindole biosynthesis is geranyl pyrophosphate (GPP), which is biosynthesized from isopentenyl pyrophosphate (IPP) and dimethylallyl pyrophosphate (DMAPP) via the MEP/DOXP pathway. Four genes (D1-4) show homology to $d x s, d x r$, isp $G$ and $i s p H$, which are proposed to biosynthesize IPP and DMAPP from pyruvate and D-glyceraldehyde-3-phosphate. The remaining genes, ispDEF, are located outside of the gene cluster in most strains (ispE was not identified in the genomes of FS ATCC43239, FA UTEX1903 and FS PCC9339). IPP and DMAPP are the substrates for the enzyme geranyl pyrophosphate synthase (GPP synthase) to produce GPP [19]. The gene P2 is also conserved across most gene clusters and was proposed to encode a GPP synthase. Recent enzymatic characterization of AmbP2 and WelP2 from the $a m b$ and wel gene clusters, respectively, confirmed our prediction that P2 encodes a GPP synthase $[7,8]$.

\section{Hapalindole-specific prenyltransferase}

The $P 1$ gene is also part of the core set of genes found in each of the hpi/amb/wel gene clusters. P1 encodes a putative prenyltransferase with sequence similarity to other previously characterized proteins belonging to the ABBA superfamily of prenyltransferases [20]. Sequence analysis of $\mathrm{P} 1$ revealed the absence of the Mg-dependent prenyl diphosphate binding motif (N/D)DXXD [21]. The prenyltransferase $\mathrm{P} 1$ in the hpi/amb/wel gene clusters was initially proposed to convert GPP (biosynthesized by P2) to $\beta$-ocimene in order to catalyze the prenylation of indole-isonitrile to produce 12-epi- hapalindole $C$ [10]. Based on the biosynthetic schemes proposed by Moore and others, we anticipated P1 to possess activity that catalyzes a reverse prenylation independent of any additional enzymatic participation, in which $\mathrm{C} 3$, rather than $\mathrm{C} 1$, of $\beta$-ocimene is attached to $\mathrm{C} 10$ of indole-isonitrile (hapalindole numbering) $[1,10]$. Recent characterization of AmbP1 and WelP1 from the $a m b$ and wel gene clusters both failed to convert GPP to $\beta$-ocimene $[7,8]$. We independently set out to characterize $\mathrm{P} 1$ from the wel gene cluster from WI HT-29-1. WelP1 was incubated with possible substrates tryptophan or indole-isonitriles with GPP at a range of temperatures and incubation times, however, no differences between the control (no enzyme) and assay were detected via LC-MS. As no product was detected, we suspected an additional enzyme was probably involved. We proposed that the enzymatic pathway for hapalindole biosynthesis involves P1 for GPP binding and activation, simultaneously coupled with a halogenating enzyme, based upon the presence of a halogenated prenyl group. A putative halogenase (WelH) in the wel gene clusters from HW IC-52-3, WI HT-29-1 and FS PCC9431 displays similarity to $\mathrm{FADH}_{2}$-dependent halogenases, containing both a FAD-binding motif (GxGxxG) and a tryptophanbinding motif (WxWxIP) [22]. $\mathrm{FADH}_{2}$-dependent halogenases require a partner enzyme, a flavin reductase, to regenerate reduced flavin from FAD and NADH $[23,24]$. Located upstream from welH, orf9 is homologous to NADH dehydrogenases, which may be a partner enzyme for WelH. This partner gene set (welH and orf9) is conserved between WI HT-29-1, HW IC-52-3 and FS PCC9431 with greater than $98 \%$ sequence identity at the protein level. Due to the absence of sequence data downstream of the published wel gene cluster from HW UTEXB1830 we were unable to establish the presence of a homologous halogenase in this strain [8].

In order to test our theory that WelH was involved in hapalindole biosynthesis, we overexpressed WelH from the wel gene cluster from WI HT-29-1. We used SsuE as the flavin reductase, as SsuE is commonly used as a flavin reductase with other $\mathrm{FADH}_{2}$-dependent halogenases from diverse genera [24]. However, biochemical assays with WelH and SsuE did not result in a halogenated product. 
Table 3 List of encoded oxygenase enzymes from the hpi, amb and wel biosynthetic gene clusters

\begin{tabular}{|c|c|c|c|c|c|c|c|c|}
\hline Enzyme & $\begin{array}{l}\text { FS ATCC } \\
43239\end{array}$ & $\begin{array}{l}\text { FS PCC } \\
9339\end{array}$ & $\begin{array}{l}\text { FA UTEX } \\
1903 \\
\end{array}$ & $\begin{array}{l}\text { HW } \\
\text { IC-52-3 }\end{array}$ & $\begin{array}{l}\text { WI } \\
\text { HT-29-1 }\end{array}$ & $\begin{array}{l}\text { FS PCC } \\
9431\end{array}$ & $\begin{array}{l}\text { FM SAG } \\
1427-1 \\
\end{array}$ & $\%$ identity \\
\hline \multicolumn{9}{|l|}{ Oxygenases } \\
\hline Rieske oxygenase & - & - & $\mathrm{AmbO1}$ & - & - & - & - & - \\
\hline Rieske oxygenase & - & - & $\mathrm{AmbO} 2$ & - & - & - & - & - \\
\hline Rieske oxygenase & - & - & $\mathrm{AmbO} 3$ & - & - & - & - & - \\
\hline Rieske oxygenase & - & $\mathrm{HpiO} 4$ & $\mathrm{AmbO} 4$ & - & - & - & - & 100 \\
\hline Oxidoreductase, 2OG-Fe(II) oxygenase family & - & $\mathrm{HpiO5}$ & AmbO5 & - & - & - & - & 98.1 \\
\hline Alkanesulfonate monooxygenase & - & HpiO6 & AmbO6 & - & - & - & - & 100 \\
\hline $\begin{array}{l}\text { Oxidoreductase, FAD dependent } \\
\text { pyridine nucleotide disulfide }\end{array}$ & - & - & $\mathrm{AmbO7}$ & - & - & - & - & - \\
\hline Rieske oxygenase & HpiO8 & HpiO8 & - & - & - & - & - & 100 \\
\hline Rieske oxygenase & HpiO9 & - & - & - & - & - & - & - \\
\hline Oxidoreductase, FAD dependent & HpiO10 & - & - & - & - & - & - & - \\
\hline Rieske oxygenase & - & - & - & WelO11 & WelO11 & - & - & 90.9 \\
\hline Rieske oxygenase & - & - & - & WelO12 & WelO12 & WelO12 & - & 99.1 \\
\hline Rieske oxygenase & - & - & - & WelO13 & WelO13 & - & & 97.8 \\
\hline Rieske oxygenase & - & - & - & WelO14 & WelO14 & WelO14 & - & 98.1 \\
\hline Oxidoreductase, 2OG-Fe(II) oxygenase family & - & - & - & WelO15 & WelO15 & WelO15 & - & 96.3 \\
\hline Indoleamine 2,3-dioxygenase & - & - & - & WelO16 & WelO16 & WelO16 & - & 99.0 \\
\hline Choline dehydrogenase-like flavoprotein & - & - & - & WelO17 & WelO17 & WelO17 & - & 99.0 \\
\hline Monooxygenase & - & - & - & - & WelO18 & - & WelO18 & 99.0 \\
\hline Rieske oxygenase & - & - & - & - & WelO19 & - & WelO19 & 98.3 \\
\hline
\end{tabular}

Additionally, biochemical assays using WelP1, WelH and SsuE were also unsuccessful. The absence of this halogenase from the hpi and $a m b$ gene clusters suggests that welH may not be involved in hapalindole biosynthesis. Recent reports by Hillwig et al. [8] suggest that the oxygenase WelO5 (numbering based on those in Hillwig et al. [8], not this paper, see below) might function to perform this role. Further investigation is required to determine the additional enzymes required for hapalindole biosynthesis with P1.

\section{Oxygenase genes}

Comparison of the hpi, amb and wel gene clusters also identified 37 genes encoding oxygenases from all eight gene clusters (excluding wel from HW UTEXB1830). Each encoded protein sequence was compared to each other, and those with an identity greater than $90 \%$ were believed to be homologous proteins, and labelled with the same number (Additional file 8). A total of 19 different oxygenase genes (O1-19) were identified (Table 3). Eleven of the 19 oxygenases (O1-4, O8-9, O11-14 and O19) were identified as Rieske-type oxygenase genes. The [2Fe-2S] cluster motif, the iron-sulfur Rieske domain and nonheme Fe(II)-binding motif were identified within the encoded protein sequence (Additional file 9). Both $\mathrm{HpiO} 4$ and AmbO4 appear to be atypical Rieske-homologous proteins. Analysis of all 19 oxygenase genes revealed none were common in all nine gene clusters. $01-3$ and 07 were found exclusively in the $a m b$ gene cluster, suggesting these oxygenases are involved in the structural diversification of the ambiguines. O4-6 were identified in the hpi gene cluster from FS PCC9339 and the $a m b$ gene cluster. Furthermore, 08 was found exclusively in both of the hpi gene clusters identified in this study. Two oxygenases, $O 9$ and 010 , were identified only in the $h p i$ gene cluster from FS ATCC43239. O12 and 014-17 were identified in three wel gene clusters (HW IC-52-3, WI HT-29-1 and PCC9339), and $O 11$ and $O 13$ have been identified in the wel gene cluster from WI HT-29-1 and HW IC-52-3. The presence of $O 11$ and $O 13$ in the wel gene cluster from FS PCC9431 was unable to be confirmed due to sequencing gaps in the oxygenase genes located at the 5 ' end of the gene cluster. Two oxygenase genes, 018 and O19, proposed to encode a monooxygenase and a Rieske-type oxygenase, were identified in the wel gene clusters from WI HT-29-1 and FM SAG1427-1. Further biochemical investigation is required to determine the specific role of each oxygenase to their respective pathway.

\section{Genes containing a domain of unknown function}

Another common feature of the hpi/amb/wel gene clusters is the presence of DUF genes. 21 DUF genes were identified from all of the gene clusters (excluding HW UTEXB1830) 
Table 4 List of unknown proteins with domain of unknown function from hpi, amb and wel clusters

\begin{tabular}{|c|c|c|c|c|c|c|c|c|}
\hline Enzyme & $\begin{array}{l}\text { FS ATCC } \\
43239\end{array}$ & $\begin{array}{l}\text { FS PCC } \\
9339\end{array}$ & $\begin{array}{l}\text { FA UTEX } \\
1903\end{array}$ & $\begin{array}{l}\text { HW } \\
\text { IC-52-3 }\end{array}$ & $\begin{array}{l}\text { WI } \\
\text { HT-29-1 }\end{array}$ & $\begin{array}{l}\text { FS PCC } \\
9431\end{array}$ & $\begin{array}{l}\text { FM SAG } \\
1427-1 \\
\end{array}$ & $\%$ identity \\
\hline \multicolumn{9}{|c|}{ Unknown proteins with DUF } \\
\hline Unknown function & HpiU1 & HpiU1 & AmbU1 & - & - & - & - & 97.7 \\
\hline Unknown function & HpiU2 & HpiU2 & AmbU2 & - & - & - & - & 98 \\
\hline Unknown function & HpiU3 & HpiU3 & AmbU3 & - & - & - & - & 99.1 \\
\hline Unknown function & - & $\mathrm{HpiU} 4$ & AmbU4 & - & - & - & - & 100 \\
\hline Unknown function & HpiU5 & - & - & - & - & - & - & - \\
\hline Unknown function & HpiU6 & HpiU6 & - & WelU6 & WelU6 & WelU6 & - & 94.2 \\
\hline Unknown function & - & - & - & WelU7 & - & - & - & - \\
\hline Unknown function & - & - & - & WelU8 & WelU8 & WelU8 & - & 97.9 \\
\hline
\end{tabular}

and each protein sequence was compared to each other and those with an identity greater than $90 \%$ were labelled with the same number (Additional file 10). A total of eight different genes (U1-8) were identified (Table 4). Although one DUF gene was not found in all gene clusters, $U 6$ was identified in all of the hpi and wel gene clusters. U1-3 were identified in both the $h p i$ and $a m b$ gene clusters, and $U 4$ was identified in the hpi gene cluster from FS PCC9339 and the $a m b$ gene cluster. $U 5$ was identified exclusively in the hpi gene cluster from FS ATCC43239, U7 was identified only in the wel gene cluster from HW IC-52-3, and U8 was identified in the wel gene clusters from HW IC-52-3, WI HT-29-1 and FS PCC9431. However, as the function of these protein-encoding genes remains unknown, their involvement in the biosynthesis of the hapalindole, fischerindoles, ambiguines and welwitindolinones remains elusive.

\section{Methytransferase genes}

The wel gene clusters identified in WI HT-29-1, HW IC-52-3 and FS PCC9431 contain three genes with homology to different methyltransferases (welM1, welM2 and welM3) (Table 2). Only welM2 was identified in the wel gene cluster from FM SAG1427-1. Although sequence downstream of the wel cluster in HW UTEXB1830 is unable to establish the presence of welM2 and welM3, we propose (on the basis of the homology of genes within each of the wel gene clusters) that welM2 and welM3 would be conserved. Hillwig et al. [8] have established that welM1 encodes the $N$-methyltransferase involved in the biosynthesis of $N$-methyl-welwitindolinone $\mathrm{C}$ isonitrile via in vitro enzymology, confirming the wel gene cluster is responsible for welwitindolinone biosynthesis. M2 is proposed to encode a SAM-dependent methyltransferase, whilst $M 3$ is proposed to encode a histamine $\mathrm{N}$-methyltransferase. The purpose of welM2 and welM3 remain unknown, as no other known compounds of the hapalindole family require an additional methylation reaction.

\section{Ambiguine biosynthesis}

The aromatic prenyltransferase AmbP3 was characterized, and shown to be responsible for catalyzing the prenylation of hapalindole $\mathrm{G}$ with DMAPP to produce the ambiguines. We identified $a m b P 3$ only in the $a m b$ gene cluster from FA UTEX1903, thus confirming this is the only species within this study with the capability to produce ambiguines.

\section{Other genes}

Three response regulator-coding genes have been identified from the nine gene clusters analyzed in this study. welR3 is unique to the wel gene clusters. However, the two regulatory genes $R 1$ and $R 2$ were identified in all hpi/amb/wel gene clusters (excluding FM SAG1427-1). The transporter genes E1-3 that were originally identified in the $a m b$ gene cluster have also been identified in the hpi gene cluster from FS PCC9339. E4, proposed to encode a small multidrug resistance protein, was identified in three wel gene clusters identified in this study (HW IC-52-3, WI HT-29-1 and FS PCC9431). C1 and C3 are proposed to encode proteins for which their function in hapalindole/ambiguine/welwitindolinone biosynthesis remains unknown.

\section{Conclusions}

The identification of the seven biosynthetic gene clusters in this study, along with the recently published $a m b$ and wel biosynthetic gene clusters, enabled bioinformatic comparisons to be performed. Organization of the wel gene clusters is distinct from the $h p i$ and $a m b$ gene clusters, which enables the prediction of which class of hapalindole-type natural products (either hapalindoles, ambiguines or welwitindolinones) may be biosynthesized from these clusters within genomes. Phylogenetic analysis indicates organisms that contain the hpi/amb/wel gene clusters form a monophyletic clade and, thus, hapalindole biosynthesis is likely to be inherited vertically, rather than horizontally. Though a conserved triad of genes (I1-I3) are present in all clusters, WelI1 and WelI3 are sufficient to 
catalyze the resulting formation of cis and trans geometrical isomers when using a cell lysate. This first report of the isolation of both cis and trans geometrical isomers for the indole-isonitrile from both enzymatic assays using WelI1 and I3 from WI HT-29-1 and from metabolic extractions of two hapalindole-producing Fischerella strains, implies the conservation of stereochemical integrity towards members of the ambiguine and welwitindolinone products, and opens new mechanistic possibilities to be studied.

This study reports new findings which are essential to the overall elucidation of the unusual mechanism of biosynthesis of the hapalindole family of compounds, however, several steps still remain elusive. At present, only a few group V cyanobacterial genomes are available. However, as more genomes are sequenced from cyanobacteria known to produce hapalindole-type natural products and further enzymology is performed, the full biosynthetic pathway to all the hapalindole-type natural products may be determined. A diverse range of oxygenases have been identified in the gene clusters reported in this study. The future enzymatic characterization of the oxygenases will most likely provide a foundation to elucidate the complex biosynthetic pathway of the hapalindole-type natural products.

\section{Methods}

\section{Cyanobacterial culturing}

The cyanobacterial strains WI HT-29-1 and HW IC-52-3 were obtained from the University of Hawaii cyanobacterial culture collection, FS ATCC43239 from American Type Culture Collection and FA UTEX1903 from Culture Collection of Algae at the University of Texas at Austin. All cyanobacterial cultures were maintained in Blue-Green 11 (BG-11) medium [25] (Fluka, Buch, Switzerland). WI HT-29-1 and HW IC-52-3 cultures were maintained at $24^{\circ} \mathrm{C}$ with $12 \mathrm{~h}$ light/dark cycles illuminated with $11 \mu \mathrm{mol} \mathrm{m} \mathrm{m}^{-2} \mathrm{~s}^{-1}$ of photons. FS ATCC43239 and FA UTEX1903 were illuminated with $80-100 \mu \mathrm{mol} \mathrm{m}^{-2} \mathrm{~s}^{-1}$ of photons on a 18:6 h light/dark cycle at $22^{\circ} \mathrm{C}$.

For extraction and isolation of biosynthetic intermediates, cyanobacterial cultures were grown in 18-20 L of BG-11 media and $4 \% \mathrm{CO}_{2}$ mixed in air was bubbled through the cultures following inoculation.

\section{Genomic DNA extraction}

Prior to genomic DNA (gDNA) extraction, WI HT-29-1 and HW IC-52-3 cyanobacterial cells were first filtered using a $3 \mu \mathrm{m}$ nitrocellulose membrane (Millipore, North Rhyde, Australia) to remove heterotrophic bacteria and washed with $200 \mathrm{~mL}$ of sterile BG-11 media. gDNA was extracted from WI HT-29-1 and HW IC-52-3 cyanobacterial cells following the protocol outlined in Morin et al. [26]. RNA was removed using $2 \mu \mathrm{L}$ of ribonuclease $\mathrm{A}$ ( $\geq 70 \mathrm{Kunitz} \mathrm{U} / \mathrm{mg}$ ) and incubated at room temperature for $15 \mathrm{~min}$. Phenol:chloroform:isoamyl alcohol extraction was performed and gDNA was precipitated using isopropanol and resuspended in TE buffer. Additional polysaccharides were removed following the protocol outlined in Wilson [27]. FS ATCC43239 gDNA was isolated following the protocol described in Ausubel et al. [28] and FA UTEX1903 gDNA was extracted following a protocol described in Mustafa [29].

\section{Whole genome sequencing and bioinformatics}

High molecular weight gDNA from WI HT-29-1 and HW IC-52-3 was sent to BGI (Beijing Genome Institute, China) for genome sequencing via high throughput Illumina sequencing technology. BGI performed genome assembly and gene annotation using Glimmer v3.0.

Extracted gDNA from FA UTEX1903 and FS ATCC43239 was submitted to Case Western Reserve Genomics Core Facility for whole genome sequencing. Paired end DNA libraries were obtained by using Nextera DNA sample preparation kit and sequenced using the Illumina GAIIx platform. Raw reads quality was assessed using FastQC 0.10.1 (Babraham Bioinformatics) with default settings and trimmed with Seqyclean 1.3.12 (http://cores.ibest. uidaho.edu/software/seqyclean). Filtered reads were assembled de novo using the velvet package (Version 1.2.08) and a kmer range between 55-63. The optimal assembly based on expected genome size, $\mathrm{N}_{50}$ and contig number was used for downstream annotation and analysis. Gene annotation was performed by BGI using Glimmer v3.2. A Basic Local Alignment Search Tool (BLAST) search was performed to identify the putative function of proteins based on sequence similarity [30].

Nucleotide and protein sequences were organized and visualized using Geneious v6.1.7 created by Biomatters. Available from http://www.geneious.com/. Nucleotide alignments were performed using Geneious Alignment with default settings. For protein alignments, Clustal Omega (Version 1.2.1) was used with default settings, except order changed from aligned to input [18].

For phylogenetic analysis, the sequences were first aligned using the Clustal W program built into Geneious. Phylogenetic trees were constructed using the Geneious Tree Builder program, which uses the neighbour-joining method [31]. A 929 bp nucleotide fragment was used for the phylogenetic analysis of $16 \mathrm{~S}$ rDNA sequences, while a 315 amino acid sequence alignment was used for phylogenetic analysis of the prenyltransferase. The outgroup was constituted by the distantly related cyanobacterium Synechocystis sp. for $16 \mathrm{~S}$ rDNA analysis.

\section{PCR and sequencing reactions}

A $50 \mu \mathrm{L}$ PCR reaction mixture contained 10 pmol of specific forward and reverse primer (Additional file 11) (Geneworks, Australia), 1× PCR Buffer (KAPA Biosystems), $2.5 \mathrm{mM} \mathrm{MgCl}_{2}, 1 \mathrm{pmol}$ dNTPs (Fisher Biotec), $1 \mathrm{U}$ of 
KapaTaq polymerase (KAPA Biosystems) and $50 \mathrm{ng}$ of gDNA template. Pfu DNA polymerase (Sigma) was used in addition to KapaTaq at a ratio of 1:10 (v/v). Hotstart PCR was performed by first heating the samples to $95^{\circ} \mathrm{C}$. Thermal cycling was then performed with a $5 \mathrm{~min}$ denaturation cycle at $95^{\circ} \mathrm{C}$, followed by 30 cycles of $95^{\circ} \mathrm{C}$ for $30 \mathrm{sec}, 55^{\circ} \mathrm{C}$ for $30 \mathrm{sec}$ and $72^{\circ} \mathrm{C}$ for 1 min per $1 \mathrm{~kb}$. Thermal cycling was concluded with a final extension at $72^{\circ} \mathrm{C}$ for $7 \mathrm{~min}$. PCR products were visualized in $1 \%$ agarose gels in TAE buffer and single bands were gel extracted and purified using the QIAquick spin gel extraction kit (QIAGEN). Single sequencing reactions were submitted to the Ramaciotti Centre for Genomics at the University of New South Wales.

\section{Gene cloning for heterologous expression}

The pJexpress411-T7-kan plasmids (with $C$ - terminal $\mathrm{His}_{6}$-tag) harboring the codon-optimized genes of well1, welI3, welP1 and welH from WI HT-29-1 were purchased (DNA2.0, Inc, USA). A recombinant plasmid harboring the $s s u E$ gene was generated by amplification from E. coli $\mathrm{K} 12$ with primers that incorporated the restriction sites $N d e \mathrm{I}$ and HindIII [32]. Amplification products were cloned into the pCR2.1 vector for sequencing, before excision and cloning into the pET28b expression vector. The cloning step permitted the fusion of the $N$-terminus of $s s u E$ to the $\mathrm{His}_{6}$-tag present within $\mathrm{pET} 28 \mathrm{~b}$.

\section{Heterologous protein expression and purification Well1 and Well3}

A $50 \%(\mathrm{v} / \mathrm{v})$ glycerol stock of BL21(DE3) transformed with the gene of interest was used to inoculate a flask containing $25 \mathrm{~mL} \mathrm{LB}$ broth supplemented with $50 \mu \mathrm{g} / \mathrm{mL}$ kanamycin. The flask was incubated at $37^{\circ} \mathrm{C}$ with shaking at $180 \mathrm{rpm}$ for $6-8 \mathrm{~h}$. This culture was added to a flask containing $1 \mathrm{~L}$ of LB broth supplemented with $50 \mu \mathrm{g} / \mathrm{mL}$ kanamycin and incubated at $37^{\circ} \mathrm{C}$ until an $\mathrm{OD}_{600}$ of approximately 0.6 was obtained. The cells were then induced with $1 \mathrm{mM}$ IPTG and grown at $16^{\circ} \mathrm{C}$ overnight. The cells were centrifuged at $6,084 \times g$ for $10 \mathrm{~min}$ and frozen at $-20^{\circ} \mathrm{C}$. The cell pellet was thawed on ice and resuspended in $50 \mathrm{mM}$ Tris buffer ( $\mathrm{pH} \mathrm{7.5)} \mathrm{containing} \mathrm{a}$ cocktail of protease inhibitors (Sigma Aldrich), $0.2 \mathrm{mM}$ TCEP, $250 \mathrm{mM} \mathrm{NaCl}$, and 10\% (v/v) glycerol. Lysozyme was added to a final concentration of $1 \mathrm{mg} / \mathrm{ml}$ and stirred until a viscous suspension was obtained. The sample was sonicated under the following cycle: [ $10 \mathrm{~s}$ pulse $+1 \mathrm{~s}$ pause) $\times 5,1 \mathrm{~min}$ cooling period] repeated five times and the cellular debris was removed by centrifugation at $57,000 \times g$ for $1 \mathrm{~h}$ at $4^{\circ} \mathrm{C}$.

\section{WelP1}

pJexpress411welP1 was freshly transformed into BL21 (DE3) cells. An individual colony was picked and protein expression was performed as outlined in Hillwig et al. [7] for protein expression. Recombinant WelP1 was purified via immobilized metal affinity chromatography using a pre-packed His GraviTrap column (GE Healthcare). Imidazole was removed via dialysis using SnakeSkin dialysis tubing (3.5 kDa cutoff) (Thermo Scientific, Rockford, USA) and concentrated using Ambicon Ultra filters. Purified protein was then snap-frozen and stored at $-80^{\circ} \mathrm{C}$.

\section{WelH and SsuE}

pJexpress411wel $\mathrm{H}$ was freshly transformed into BL21 (DE3) cells, and a single colony was used to inoculate $50 \mathrm{~mL}$ of LB media supplemented with $50 \mu \mathrm{g} / \mathrm{mL}$ kanamycin. The flask was incubated at $37^{\circ} \mathrm{C}$ with shaking at $180 \mathrm{rpm}$ for $7.5 \mathrm{~h} .25 \mathrm{~mL}$ of this culture was then used to inoculate $1 \mathrm{~L}$ of LB media supplemented with $50 \mu \mathrm{g} / \mathrm{mL}$ kanamycin, and incubated at $37^{\circ} \mathrm{C}$ until an $\mathrm{OD}_{600}$ of approximately 0.6 was obtained. Protein expression was then induced with $1 \mathrm{mM}$ IPTG and grown at $16^{\circ} \mathrm{C}$ overnight. The cells were then collected by centrifugation at $8,000 \times g$ for $10 \mathrm{~min}$ at $4^{\circ} \mathrm{C}$. Cell pellets were thawed on ice and resuspended in $50 \mathrm{mM}$ Tris $(\mathrm{pH} 7.5), 0.5 \mathrm{mM}$ PMSF, $250 \mathrm{mM} \mathrm{NaCl}$ and 10\% (v/v) glycerol. Lysozyme was then added to a final concentration of $1 \mathrm{mg} / \mathrm{mL}$. Once a viscous suspension was achieved, cells were lysed via sonication (5× $10 \mathrm{sec}$ pulse with $1 \mathrm{sec}$ pause, $1 \mathrm{~min}$ cooling period, repeated four times). The cellular debris was removed by centrifugation at $8,000 \times g$ at $4^{\circ} \mathrm{C}$ for $30 \mathrm{~min}$. The imidazole concentration of the soluble protein fraction was first adjusted to $10 \mathrm{mM}$. Purification was then performed using His GraviTrap column (GE Healthcare). After the soluble protein was run through the column, $50 \mathrm{mM}$ Tris ( $\mathrm{pH} 7.5$ ), $10 \mathrm{mM}$ imidazole, $250 \mathrm{mM} \mathrm{NaCl}$ and $10 \%$ glycerol was used to wash the column. The beads were then washed with increasing concentrations of imidazole to remove contaminating proteins $(25$ and $50 \mathrm{mM}$ imidazole). WelH was then eluted from the column by addition of $10 \mathrm{~mL}$ of $50 \mathrm{mM}$ Tris ( $\mathrm{pH} 7.5), 100 \mathrm{mM}$ imidazole, $250 \mathrm{mM} \mathrm{NaCl}$ and $10 \%$ glycerol and $10 \mathrm{~mL}$ of $50 \mathrm{mM}$ Tris ( $\mathrm{pH} 7.5$ ), $250 \mathrm{mM}$ imidazole, $250 \mathrm{mM} \mathrm{NaCl}$ and $10 \%$ glycerol. These fractions were then combined and dialyzed against $20 \mathrm{mM}$ Tris ( $\mathrm{pH}$ 7.5), $0.2 \mathrm{mM}$ TCEP, $250 \mathrm{mM} \mathrm{NaCl}$ and 20\% glycerol using SnakeSkin dialysis tubing (3.5 kDa cutoff) (Thermo Scientific, Rockford, USA). The protein was then snap frozen and stored at $-80^{\circ} \mathrm{C}$.

pET28bssuE was also freshly transformed into BL21 (DE3) cells and protein expression and purification was performed as outlined in Dorrestein et al. [32].

\section{Enzymatic assay with cell lysates (Well1 and Well3)}

Each cell lysate containing a protein of interest (WelI1 or WelI3) totaled approximately $10 \mathrm{~mL}$ (resulting from $1 \mathrm{~L}$ of culture). Assay components were mixed to a final 
reaction volume of $5 \mathrm{~mL}(1 \mathrm{~mL}$ Well1 cell lysate, $1 \mathrm{~mL}$ WelI3 cell lysate, $25 \mathrm{mM}$ Tris (pH 7.0), $150 \mathrm{mM} \mathrm{NaCl}$, $0.8 \mathrm{mg} / \mathrm{ml} \mathrm{L}$-tryptophan, $0.8 \mathrm{mg} / \mathrm{ml}$ ribose-5-phosphate, $0.8 \mathrm{mg} / \mathrm{ml} \alpha$-ketoglutaric acid, $25 \mu \mathrm{M}$ (ammonium iron (II) sulphate). Samples were then incubated for $16 \mathrm{~h}$ at $25^{\circ} \mathrm{C}$ and extracted with 1:1 isopropanol/hexanes. Following extraction, samples were analyzed by HPLC. A negative control was performed with E. coli BL21 (DE3) cell lysate hosting no plasmid.

\section{WelP1, WelH and SsuE enzymatic assay}

For WelP1 assay only, $1 \mathrm{mM}$ mixture of cis and trans isomers of indole-isonitrile standard, $1 \mathrm{mM} \mathrm{GPP,} 0$ and $5 \mathrm{mM} \mathrm{MgCl}_{2}, 100 \mathrm{mM}$ Tris (pH 7.5), $2 \mathrm{mM}$ DTT and $15 \mu \mathrm{g}$ of WelP1. The assay was incubated at 26 and $30^{\circ} \mathrm{C}$ for 1 and $16 \mathrm{~h}$.

$1 \mu \mathrm{M}$ WelP1, $1 \mu \mathrm{M}$ WelH and $3 \mu \mathrm{M}$ SsuE was added to a $500 \mu \mathrm{L}$ reaction containing $1 \mathrm{mM}$ mixture of cis and trans isomers of indole-isonitrile standard, $1 \mathrm{mM}$ GPP, $5 \mathrm{mM} \mathrm{MgCl}$, $20 \mathrm{mM}$ Tris (pH 7.5), $25 \mathrm{mM} \mathrm{NaCl}$, $2.4 \mathrm{mM} \beta$-nicotinamide adenine dinucleotide, reduced dipotassium salt (NADH) and $20 \mu \mathrm{M}$ flavin adenine dinucleotide disodium salt hydrate (FAD). The enzymatic assay was incubated at $26^{\circ} \mathrm{C}$ for both $3 \mathrm{~h}$ and $5 \mathrm{~h}$ and $30^{\circ} \mathrm{C}$ for $3 \mathrm{~h}$.

Attempts to optimize this assay included altering the concentration of enzymes (1-2 $\mu \mathrm{M}$ WelP1 and WelH, 3-6 $\mu \mathrm{M} \mathrm{SsuE),} \mathrm{the} \mathrm{concentration} \mathrm{of} \mathrm{the} \mathrm{starting} \mathrm{com-}$ pounds $(0.5 \mathrm{mM}$ mixture of cis and trans isomers of indole-isonitrile and $0.5 \mathrm{mM} \mathrm{GPP})$, the concentration of $\mathrm{NaCl}(0$ and $25 \mathrm{mM}$ ), the concentration of NADH (2.4 and $10 \mathrm{mM}$ ) and the addition of $5 \%$ glycerol at 26 and $30^{\circ} \mathrm{C}$ for $15 \mathrm{~h}$.

WelH and SsuE were also tested against L-tryptophan and GPP with and without WelP. In this assay, $1 \mu \mathrm{M}$ WelH and $3 \mu \mathrm{M}$ SsuE was added to a $500 \mu \mathrm{L}$ reaction containing either $1 \mathrm{mM}$ L-tryptophan or $1 \mathrm{mM}$ GPP, $20 \mathrm{mM}$ Tris (pH 7.5), $25 \mathrm{mM} \mathrm{NaCl}, 2.4 \mathrm{mM} \mathrm{NADH}$ and $20 \mu \mathrm{M}$ FAD. 0 and $1 \mu \mathrm{M}$ WelP was also added. The enzymatic assay was incubated at both 26 and $30^{\circ} \mathrm{C}$ for $3 \mathrm{~h}$ and extracted as per WelP1, WelH and SsuE assay above.

We also attempted the assay using the isonitrile proteins WelI1 and WelI3 with WelP1. 60 ng WelI1, 60 ng WelI3, $3 \mathrm{nM}$ WelP1 was added to $0.8 \mathrm{mg} / \mathrm{mL}$ L-tryptophan, $1 \mathrm{mM}$ GPP, $0.8 \mathrm{mg} / \mathrm{mL}$ D-ribose-5-phosphate disodium salt hydrate, $0.8 \mathrm{mg} / \mathrm{mL} \alpha$-ketoglutarate, $25 \mu \mathrm{M}$ iron ammonium sulphate hexahydrate, $25 \mathrm{mM}$ Tris (pH 7.5), $150 \mathrm{mM} \mathrm{NaCl}, 5 \mathrm{mM} \mathrm{MgCl}_{2}$, in $500 \mathrm{uL}$ reaction. The reaction was performed for $16 \mathrm{~h}$ at $26^{\circ} \mathrm{C}$. The assay was also attempted using $3 \mathrm{nM} \mathrm{WelH}$ and $9 \mathrm{nM}$ SsuE.

All enzymatic products were extracted with three volumes of $1 \%$ acetic acid in ethyl acetate twice, dried, redissolved in $600 \mu \mathrm{L}$ of methanol, and filtered through $0.2 \mu \mathrm{m}$ PVDF filters (Grace Davison Discovery Sciences,
USA). The extracted products were analyzed at the UWS MS Facility, Australia. Mass spectrometric analysis was undertaken using a Waters Xevo TQ-MS triple quadrupole instrument. Methanolic solutions were directly infused at $5 \mu \mathrm{L} / \mathrm{min}$ and data for each sample was recorded over the range $m / z 10-500$ in MS1 mode for a period of $10 \mathrm{~min}$. Positive ion spectra were recorded with the following parameters: capillary voltage $3.50 \mathrm{kV}$; cone voltage $25 \mathrm{~V}$; desolvation temperature $150^{\circ} \mathrm{C}$; desolvation gas flow $400 \mathrm{~L} / \mathrm{hr}$; cone gas flow $0 \mathrm{~L} / \mathrm{hr}$. Negative ion spectra were recorded with the following parameters: capillary voltage $3.00 \mathrm{kV}$; cone voltage $20 \mathrm{~V}$; desolvation temperature $300^{\circ} \mathrm{C}$; desolvation gas flow $550 \mathrm{~L} / \mathrm{hr}$; cone gas flow $5 \mathrm{~L} / \mathrm{hr}$.

\section{Indole-isonitrile metabolite extraction from FS ATCC43239 and FA UTEX1903}

Fresh biomass was collected from FS ATCC43239 and FA UTEX1903 cultures by centrifugation at 3,500 $\times g$ for $10 \mathrm{~min}$ and then extracted with $60 \%(\mathrm{v} / \mathrm{v})$ aqueous acetonitrile for $24 \mathrm{~h}$ at $4^{\circ} \mathrm{C}$. Acetonitrile was removed using rotary evaporation and the collected aqueous layer was extracted with three equal volumes of ethyl acetate. After removal of ethyl acetate in vacuo, residue was stored at $-80^{\circ} \mathrm{C}$, until subjected to fractionation. For purification, silica gel was quenched with $0.5 \%$ triethyl amine in ethyl acetate:hexane mixture (5:94.5). Fractions were collected in $5 \%, 10 \%, 20 \%, 30 \%, 40 \%$ and $50 \%$ ethyl acetate/hexane gradient. Fractions with indole-isonitrile co-eluted at $40 \%$ ethyl acetate/hexane (alongside few other metabolites). Collected fractions were further purified by silica gel (quenched with 5\% triethyl amine) chromatography and the fractions containing indole-isonitrile were analyzed through LCMS and HRMS.

\section{LC-MS, HRESI-MS and HPLC Analyses}

Accurate LC-MS data of cyanobacterial extracts were recorded with a Waters Acquity I-Class UPLC system and a Waters Synapt G2 HDMS mass spectrometer. High-resolution electrospray ionization-mass spectrometry (HRESI-MS) data for synthetic compounds and cyanobacterial extracts were obtained by direct infusion of methanolic solutions on a Waters Synapt HDMS QTOF mass spectrometer (Waters Corporation, Milford, MA). HPLC analyses for synthetic intermediates were performed using a Shimadzu LC-20-AT Series separations module equipped with Shimadzu SPD-M20A PDA (photo diode array) multiple wavelength detectors $(180 \mathrm{~nm}-800 \mathrm{~nm})$. For indole-isonitrile compounds, UV detector was set at $310 \mathrm{~nm}$ with a $5 \mathrm{~nm}$ slit-width. The overall system, CBM20 was controlled using LC Solutions software. Raw data was plotted using Origin ${ }^{\circ}$ software program after exporting absorbance data as an ASCII-formatted file. Analytical separations of stereoisomers (of cis and trans) mixtures were carried out on Daicel $^{\circ}$ (normal phase) AS chiral 
column. A 10\% isopropanol/ $90 \%$ hexanes mixture was used as elution medium with a flow rate of $1 \mathrm{~mL} / \mathrm{min}$ in an isocratic mode. Individual retention times for indoleisonitriles are reported along with analytical data for each isomer.

\section{Synthesis and spectroscopic analysis of indole-isonitrile}

Anhydrous tetrahydrofuran was obtained from mBraun solvent purification system (A2 alumina). Reactions were monitored by thin-layer chromatography (TLC) on silica gel plates $\left(60 \mathrm{~F}_{254}\right)$ with a fluorescent indicator, and independently visualized with UV light. Preparatory thin-layer chromatography (TLC) was performed on glass plates $(7.5 \times 2.5$ and $7.5 \times 5.0 \mathrm{~cm})$ pre-coated glass plates coated with $60 \AA$ Ailica gel (Whatman). Separations of isonitrile intermediates were carried out using flash chromatography (Silica gel grade: $200-400$ mesh, 40-63 $\mu \mathrm{m}$ ) at medium pressure $(20 \mathrm{psi})$. NMR spectra were recorded at $400 \mathrm{MHz}$ in $\mathrm{CDCl}_{3}$ and chemical shift values $(\delta)$ are reported in ppm. ${ }^{1} \mathrm{H}$ NMR spectra are reported in parts per million $(\delta)$ relative to the residual (indicated) solvent peak. Data for ${ }^{1} \mathrm{H}$ NMR are reported as follows: chemical shift $(\delta \mathrm{ppm})$, multiplicity $(\mathrm{s}=$ singlet, brs $=$ broad singlet, $\mathrm{d}=$ doublet, $\mathrm{t}=$ triplet, $\mathrm{q}=$ quartet, $\mathrm{ddd}=$ double double doublet, $\mathrm{m}=$ multiplet, $\mathrm{cm}=$ complex multiplet), integration, and coupling constants in $\mathrm{Hz} .{ }^{13} \mathrm{C}$ NMR spectra were obtained on $400 \mathrm{MHz}$ spectrometers $(100 \mathrm{MHz}$ actual frequency) and are reported in parts per million $(\delta)$ relative to the residual (indicated) solvent peak. Highresolution mass spectrometry (HRMS) data were obtained on spectrometer with a quadrupole analyzer.

\section{Synthesis of cis and trans isomers of indole-isonitrile 3-Indolecarbaldehyde synthesis}

To $7 \mathrm{~mL}$ of $N$, N-dimethylformamide (DMF), $1 \mathrm{~mL}$ of phosphorus oxychloride $\left(\mathrm{POCl}_{3}\right)$ was added drop-wise at $0^{\circ} \mathrm{C}$. The mixture was stirred for $20 \mathrm{~min}$, after which $3 \mathrm{~mL}$ of $10 \mathrm{mmol}$ indole in DMF was added dropwise to the mixture. After the mixture was stirred at $35^{\circ} \mathrm{C}$ for $1 \mathrm{~h}$, crushed ice was added, followed by $20 \%$ aq. sodium hydroxide $(\mathrm{NaOH})$ and the mixture was refluxed for $6 \mathrm{~h}$ maintained at $35^{\circ} \mathrm{C}$. On cooling, the mixture was poured into ice water, and the precipitated product was collected, washed by water, and dried. 3-indolecarbaldehyde was the sole product and was isolated in $84 \%$ yield. This product was sufficiently pure for subjection to isonitrile formation step as shown from its ${ }^{1} \mathrm{H}$ NMR spectrum. ${ }^{1} \mathrm{H}$ NMR (400 MHz, DMSO-d6): $\delta 9.97$ (s, 1H), 8.33 (s, 1H), $8.13(\mathrm{~d}, J=7.6 \mathrm{~Hz}, 1 \mathrm{H}), 7.55$ (d, $J=7.2 \mathrm{~Hz}, 1 \mathrm{H}), 7.31-7.24$ (m, 2H).

\section{Synthesis of indole-isonitrile (3-(2-isocyanovinyl)indole)}

A $5 \mathrm{~mL}$ THF solution containing $584 \mathrm{mg}(3.3 \mathrm{mmol}$, 1.1 equiv.) of diethyl (isocyanomethyl) phosphonate was added drop wise to a stirred solution containing $839 \mathrm{mg}$
(4.57 mmol, 1.5 equiv.) of sodium bis (trimethylsilyl)amide in $5 \mathrm{~mL}$ of $\mathrm{THF}$ at $-78^{\circ} \mathrm{C}$. The resulting mixture was stirred for $15 \mathrm{~min}$ and then treated with a solution of $436 \mathrm{mg}$ (3.0 mmol, 1.0 equiv.) of 3-indolecarbaldehyde in $30 \mathrm{~mL}$ of THF. The solution was allowed to warm to $4^{\circ} \mathrm{C}$ and allowed to stir for an additional 48 h. $198 \mathrm{mg}$ (3.3 mmol) of acetic acid in $1.5 \mathrm{~mL}$ of THF was added to quench the reaction. The solvent was removed in vacuo, the residue was dissolved in $30 \mathrm{~mL}$ of ethyl acetate, washed with $15 \mathrm{~mL}$ of $0.1 \mathrm{M}$ phosphate buffer $(\mathrm{pH}=7.2)$, then with $15 \mathrm{~mL}$ of $\mathrm{H}_{2} \mathrm{O}$ and the resulting organic layer was dried on a bed of $\mathrm{MgSO}_{4}$. Collected organic layer was evaporated to obtain the crude product which upon purification through chromatography (silica gel) eluting with a gradient of $10-12 \%$ ethyl acetate in hexane yielded a mixture of trans (196 mg, 45\%) and cis (106 mg, 25\%) indole-isonitrile in a 3:2 ratio as indicated by ${ }^{1} \mathrm{H}$ NMR analysis and in $70 \%$ overall yield.

\section{trans indole-isonitrile synthesis}

${ }^{1} \mathrm{H}$ NMR (400 MHz, CDCl $) \delta 8.35$ (brs, $\left.1 \mathrm{H}\right), 7.69$ (d, $7.9 \mathrm{~Hz}, 1 \mathrm{H}), 7.44-7.40(\mathrm{~m}, 1 \mathrm{H}), 7.35(\mathrm{~d}, J=2.6 \mathrm{~Hz}, 1 \mathrm{H})$, 7.32-7.21 (m, 2H), $7.14(\mathrm{~d}, J=14.2 \mathrm{~Hz}, 1 \mathrm{H}), 6.36(\mathrm{~d}, J=$ $14.2 \mathrm{~Hz}, 1 \mathrm{H}) .{ }^{13} \mathrm{C}$ NMR $\left(100 \mathrm{MHz}, \mathrm{CDCl}_{3}\right) \delta 163.3,137.0$, $130.3,126.4,124.8,123.6,121.6,120.1,112.0,111.3,107.3$ (Additional file 5).

\section{cis indole-isonitrile synthesis}

${ }^{1} \mathrm{H}$ NMR (400 MHz, $\left.\mathrm{CDCl}_{3}\right) \delta 8.56$ (brs, $\left.1 \mathrm{H}\right), 8.15$ (d, $2.8 \mathrm{~Hz}, 1 \mathrm{H}), 7.68$ (d, $7.9 \mathrm{~Hz}, 1 \mathrm{H}), 7.44(\mathrm{~d}, J=7.9 \mathrm{~Hz}$, $1 \mathrm{H})$, 7.32-7.20 (m, 2H), 6.84-6.75 (m, 1H), $5.75(\mathrm{~d}, J=$ $8.8 \mathrm{~Hz}, 1 \mathrm{H}) .{ }^{13} \mathrm{C}$ NMR $\left(100 \mathrm{MHz}, \mathrm{CDCl}_{3}\right) \delta 169.1,135.2$, $126.9,126.5,124.2,123.4,121.1,118.2,111.6,110.3,104.6$ (Additional file 5).

The $\mathrm{R}_{f}$ value (40\% EtOAC in hexanes) for the cis isomer of isonitrile is: 0.52 , and the $\mathrm{R}_{f}$ value $(40 \% \mathrm{EtOAC}$ in hexanes) for the trans isomer of isonitrile is: 0.36. These $\mathrm{R}_{f}$ values were applied for identification and comparison of isonitriles in metabolic extracts from FS ATCC43239 and FA UTEX1903 cyanobacterial strains as described in this study. The ${ }^{1} \mathrm{H}$ NMR spectra and ${ }^{13} \mathrm{C}$ NMR data of the synthesized standard matched those reported by Hoppe and Schollkopf [33].

\section{Nucleotide sequence accession numbers}

The nucleotide sequence of the gene clusters were deposited to NCBI GenBank under the following accession numbers: KJ742064 for FS ATCC43239, JK742065 for FA UTEX1903, KJ767018 for WI HT-29-1 and KJ767017 for HW IC-52-3. The nucleotide sequence of the $16 \mathrm{~S}$ ribosomal RNA gene was also deposited to NCBI GenBank under the following accession numbers: KJ768872 for FS ATCC43239, KJ768871 for FA UTEX1903, KJ767016 for WI HT-29-1 and KJ767019 for HW IC-52-3. 


\section{Additional files}

Additional file 1: BLASTx analysis of gene clusters analyzed in this study. Table S1. The wel gene cluster in Westiella intricata UH strain HT-29-1. Table S2. The wel gene cluster in Hapalosiphon welwitschii UH strain IC-52-3. Table S3. The hpi gene cluster in Fischerella sp. ATCC 43239. Table S4. The amb gene cluster in Fischerella ambigua UTEX 1903 from this study. Table S5. The hpi gene cluster in Fischerella sp. PCC 9339. Table S6. The wel gene cluster in Fischerella sp. PCC 9431. Table S7. The wel gene cluster in Fischerella muscicola SAG 1427-1.

Additional file 2: Phylogenetic analysis of HpiP1/AmbP1/WelP1 enzyme.

Additional file 3: Sequence alignment and identification of conserved motifs from isonitrile proteins 11 and $\mathbf{I}$.

Additional file 4: Sequence alignment of isonitrile protein 13 with IsnB and PvcB.

Additional file 5: ${ }^{1} \mathrm{H}$ and ${ }^{13} \mathrm{C}$ NMR and HRMS spectra for chemically synthesized cis and trans indole-isonitriles.

Additional file 6: LC-ESI-MS spectrum for enzyme-catalyzed indole-isonitrile biosynthesis product.

Additional file 7: HRESI-MS and MS peaks from LC-MS spectra for chemically synthesized indole-isonitrile and cyanobacterial extracts from FS ATCC43239 and FA UTEX1903.

Additional file 8: Sequence identity of all oxygenase proteins. Additional file 9: Sequence alignment and identification of motifs from Reiske-type oxygenases.

Additional file 10: Sequence identity of all unknown proteins with domain of unknown function.

Additional file 11: Specific primers used in this study.

\section{Competing interests}

The authors declare that they have no competing interests.

\section{Authors' contributions}

MCM and RV designed the overall project. MLM and MCM sequenced the genomes of WI HT-29-1 and HW IC-52-3. DS and RV sequenced the genomes of FA UTEX1903 and FS ATCC43239. MLM and DS jointly contributed to identification and functional assignment of the gene clusters. MLM and LG jointly contributed to protein expression of WeIP1, WelH and SsuE. BMB contributed to the functional assignment, protein expression and reconstitution of Well1 and Well3. DS contributed to chemical synthesis and characterization of cyanobacterial extracts. MCM, LG and RV edited the final version of the manuscript drafted jointly by MLM, DS and BMB. All authors read and approved the final manuscript.

\section{Acknowledgements}

We thank Prof William Gerwick for valuable discussions and Dr Paul D'Agostino for advice and editing the manuscript. Prof. Thomas Hemscheidt and Dr Benjamin Philmus assisted with providing University of Hawaii strains. MCM and MLM thank Dr Colin Stack, Dr David Harman and Dr Emily Monroe for valuable discussions and help. RV, DS and BMB thank Kathryn Howard and Dr. Ormond Brathwaite for valuable discussions and BMB thanks DOE for a GAANN fellowship (2012-2013). Funding for supplies for expression work performed by MLM in LG's laboratory was provided by NIH (NCI) CA108874. RV, DS and BMB were funded by Case Western Reserve University. MCM and MLM were funded by the University of Western Sydney HDR Scholarship and RTS funding and the Australian Research Council, Discovery Project DP0880264.

\section{Author details}

${ }^{1}$ School of Science and Health, University of Western Sydney, School of Science and Health, Locked Bag 1797, 2751 Penrith, NSW, Australia. ${ }^{2}$ Department of Chemistry, Case Western Reserve University, 2740 Millis Science Center, Adelbert Road, 44106 Cleveland, OH, USA. ${ }^{3}$ Center for Marine Biotechnology and Biomedicine, Scripps Institution of Oceanography, University of California San Diego, 92093 La Jolla, CA, USA.
Received: 13 May 2014 Accepted: 22 July 2014

Published: 1 August 2014

\section{References}

1. Richter JM, Ishihara Y, Masuda T, Whitefield BW, Llamas T, Pohjakallio A, Baran PS: Enantiospecific total synthesis of the hapalindoles, fischerindoles, and welwitindolinones via a redox economic approach. J Am Chem Soc 2008, 130:17938-17954.

2. Smith CD, Zilfou JT, Stratmann K, Patterson GM, Moore RE: Welwitindolinone analogues that reverse P-glycoprotein-mediated multiple drug resistance. Mol Pharmacol 1995, 47:241-247.

3. Zhang $X$, Smith CD: Microtubule effects of welwistatin, a cyanobacterial indolinone that circumvents multiple drug resistance. Mol Pharmacol 1996, 49:288-294.

4. Mo S, Krunic A, Santarsiero BD, Franzblau SG, Orjala J: Hapalindole-related alkaloids from the cultured cyanobacterium Fischerella ambigua. Phytochemistry 2010, 71:2116-2123.

5. Mo S, Krunic A, Chlipala G, Orjala J: Antimicrobial ambiguine isonitriles from the cyanobacterium Fischerella ambigua. J Nat Prod 2009, 72:894-899.

6. Kim H, Lantvit D, Hwang CH, Kroll DJ, Swanson SM, Franzblau SG, Orjala J: Indole alkaloids from two cultured cyanobacteria, Westiellopsis sp and Fischerella muscicola. Bioorg Med Chem 2012, 20:5290-5295.

7. Hillwig ML, Zhu Q, Liu X: Biosynthesis of ambiguine indole alkaloids in cyanobacterium Fischerella ambigua. ACS Chem Biol 2013, 9:372-377.

8. Hillwig ML, Fuhrman HA, Ittiamornkul K, Sevco TJ, Kwak DH, Liu X: Identification and characterization of a welwitindolinone alkaloid biosynthetic gene cluster in the stigonematalean cyanobacterium Hapalosiphon welwitschii. Chem Bio Chem 2014, 15:665-669.

9. Becher $P G$, Keller $S$, Jung $G$, Süssmuth RD, Jüttner F: Insecticidal activity of 12-epi-hapalindole J isonitrile. Phytochemistry 2007, 68:2493-2497.

10. Stratmann K, Moore RE, Bonjouklian R, Deeter JB, Patterson GML, Shaffer S, Smith CD, Smitka TA: Welwitindolinones, unusual alkaloids from the blue-green algae Hapalosiphon welwitschii and Westiella intricata: relationship to fischerindoles and hapalinodoles. J Am Chem Soc 1994, 116:9935-9942.

11. Rantala A, Fewer DP, Hisbergues M, Rouhiainen L, Vaitomaa J, Börner T, Sivonen K: Phylogenetic evidence for the early evolution of microcystin synthesis. Proc Natl Acad Sci U S A 2004, 101:568-573.

12. Murray SA, Mihali TK, Neilan BA: Extraordinary conservation, gene loss, and positive selection in the evolution of an ancient neurotoxin. $\mathrm{Mol} \mathrm{BiO}$ Evol 2011, 28:1173-1182.

13. D'Agostino PM, Moffitt MC, Neilan BA: Current Knowledge of Paralytic Shellfish Toxin Biosynthesis, Molecular Detection and Evolution. In Toxins and Biologically Active Compounds from Microalgae, Volume 1. Boca Raton, FL: CRC Press; 2014:251-280.

14. Huber U, Moore RE, Patterson GML: Isolation of a nitrile-containing indole alkaloid from the terrestrial blue-green alga Hapalosiphon delicatulus. J Nat Prod 1998, 61:1304-1306.

15. Hall GC, Flick MB, Gherna RL, Jensen RA: Biochemical diversity for biosynthesis of aromatic amino acids among the cyanobacteria. J Bacteriol 1982, 149:65-78.

16. Brady SF, Clardy J: Cloning and heterologous expression of isocyanide biosynthetic genes from environmental DNA. Angew Chem 2005, 117:7225-7227.

17. Clarke-Pearson MF, Brady SF: Paerucumarin, a new metabolite produced by the pvc gene cluster from Pseudomonas aeruginosa. J Bacterio/ 2008, 190:6927.

18. McWilliam H, Li W, Uludag M, Squizzato S, Park YM, Buso N, Cowley AP, Lopez R: Analysis tool web services from the EMBL-EBI. Nucleic Acids Res 2013, 41:W597-W600.

19. Daum M, Herrmann S, Wilkinson B, Bechthold A: Genes and enzymes involved in bacterial isoprenoid biosynthesis. Curr Opin Chem Biol 2009, 13:180-188

20. Tello M, Kuzuyama T, Heide L, Noel J, Richard S: The ABBA family of aromatic prenyltransferases: broadening natural product diversity. Cell Mol Life Sci 2008, 65:1459-1463.

21. Pojer F, Wemakor E, Kammerer B, Chen H, Walsh CT, Li S-M, Heide L: CloQ, a prenyltransferase involved in clorobiocin biosynthesis. Proc Natl Acad Sci U S A 2003, 100:2316-2321.

22. Kling E, Schmid C, Unversucht S, Wage T, Zehner S, Pee KH: Enzymatic Incorporation of Halogen Atoms into Natural Compounds. In 
Biocombinatorial Approaches for Drug Finding, Volume 51. Edited by Wohlleben W, Spellig T, Müller-Tiemann B. Berlin Heidelberg: Springer; 2005:165-194. Springer Series on Biofilms.

23. Keller S, Wage T, Hohaus K, Hölzer M, Eichhorn E, van Pée K-H: Purification and partial characterization of tryptophan 7-halogenase ( $\mathrm{PrnA}$ ) from Pseudomonas fluorescens. Angew Chem Int Edit 2000, 39:2300-2302.

24. van Pée K-H, Patallo E: Flavin-dependent halogenases involved in secondary metabolism in bacteria. Appl Microbiol Biotechnol 2006 70:631-641.

25. Rippka R, Deruelles J, Waterbury JB, Herdman M, Stanier RY: Generic assignments, strain histories and properties of pure cultures of cyanobacteria. J Gen Microbiol 1979, 111:1-61.

26. Morin N, Vallaeys T, Hendrickx L, Natalie L, Wilmotte A: An efficient DNA isolation protocol for filamentous cyanobacteria of the genus Arthrospira. J Microbiol Methods 2010, 80:148-154.

27. Wilson K: Preparation of Genomic DNA from Bacteria. In Current Protocols in Molecular Biology. New York: John Wiley \& Sons, Inc; 2001

28. Ausubel F, Brent R, Kingston R, Moore D, Seidman J, Smith J, Struhl K: Short Protocols in Molecular Biology. 3rd edition. New York: John Wiley \& Sons; 1996.

29. Mustafa E: Ambigols A-C and Tjipanazole D: Bioinformatic Analysis of their Putative Biosynthetic Gene Clusters, PhD thesis. Germany: University of Bonn, Institute for Pharmaceutical Biology; 2011.

30. Altschul SF, Gish W, Miller W, Myers EW, Lipman DJ: Basic local alignment search tool. J Mol Biol 1990, 215:403-410.

31. Jukes TH, Cantor CR: Evolution of Protein Molecules. New York: Academic; 1969.

32. Dorrestein PC, Yeh E, Garneau-Tsodikova S, Kelleher NL, Walsh CT: Dichlorination of a pyrrolyl-S-carrier protein by $\mathrm{FADH}_{2}$-dependent halogenase PltA during pyoluteorin biosynthesis. Proc Natl Acad Sci U S A 2005, 102:13843-13848.

33. Hoppe I, Schöllkopf U: Synthesis and biological activities of the antibiotic B 371 and its analogs. Liebigs Ann Chem 1984, 1984:600-607.

34. Drake EJ, Gulick AM: Three-dimensional structures of Pseudomonas aeruginosa PvcA and PvcB, two proteins involved in the synthesis of 2-isocyano-6,7-dihydroxycoumarin. J Mol Biol 2008, 384:193-205.

doi:10.1186/s12866-014-0213-7

Cite this article as: Micallef et al: Comparative analysis of hapalindole, ambiguine and welwitindolinone gene clusters and reconstitution of indole-isonitrile biosynthesis from cyanobacteria. BMC Microbiology 2014 14:213.

\section{Submit your next manuscript to BioMed Central and take full advantage of:}

- Convenient online submission

- Thorough peer review

- No space constraints or color figure charges

- Immediate publication on acceptance

- Inclusion in PubMed, CAS, Scopus and Google Scholar

- Research which is freely available for redistribution 